\title{
Evaluation of the Influence of Post-Cracking Response of Steel Fibre Reinforced Concrete (SFRC) on Load Carrying Capacity of SFRC Panels
}

\author{
Hamidreza Salehian ${ }^{1}$, Joaquim A. O. Barros ${ }^{2}$, Mahsa Taheri ${ }^{3}$ \\ ${ }^{1}$ PhD Candidate (corresponding author), ISISE, Department of Civil Engineering, University of Minho, Guimarães, Portugal, e- \\ mail: h.r.salehian@gmail.com. \\ ${ }^{2}$ Full Professor, ISISE, Department of Civil Engineering, University of Minho, Guimarães, Portugal, e-mail: \\ barros@ civil.uminho.pt. \\ ${ }^{3} \mathrm{PhD}$ Candidate, ISISE, Department of Civil Engineering, University of Minho, Guimarães, Portugal, e-mail: \\ taheri.mahsa09@gmail.com.
}

\begin{abstract}
:
To develop a reliable methodology for the design of steel fibre reinforced concrete (SFRC) slabs, an extensive experimental program was carried out with SFRC square panels simply supported in their contour. By adopting a moment-rotation approach, a numerical model was developed capable of taking into account the constitutive laws of the SFRC for the prediction of the force-deflection response of variety of panel tests recommended in the international standards. The predictive performance of the model was assessed by considering results available in the bibliography and those obtained on the experimental program. The proposed model was utilized in a parametric study to assess the influence of toughness classes of SFRC on the behaviour at serviceability limit conditions, on the load carrying capacity, and on the deformational response of SFRC round panels.
\end{abstract}

Keywords: Steel fibre reinforced concrete, Post cracking response, Numerical model, Energy absorption, Square panel, Round panel 


\section{Introduction}

In the last decades, the remarkable advances in the technology of steel fibre reinforced concrete (SFRC) have enlarged the use of this composite in numerous fields of application in civil engineering. Steel fibres of different shapes, geometries, and ultimate tensile strength are being used as a discrete reinforcement to arrest the crack propagation in concrete matrix, and to provide a significant post-cracking residual strength without extra costs on the propagation and installation of this reinforcement. These benefits can be mobilised to construct more durable and cost competitive structures [1-3]. In fact, the fibres offer resistance to the coalescence of micro-cracks in mesocracks, and on the opening of these cracks towards macro-cracks. During this fracture process, the fibre pullout mechanisms assure a noticeable increase of the post-cracking fracture energy of cement based materials [4, 5]. In particular, SFRC of high post-cracking residual tensile strength can be developed by using relatively high content of steel fibres of large aspect ratio (length/diameter) in compositions designed to optimize the fibre reinforcement mechanisms [6]. A noticeable post-cracking response of SFRC can assure an ultimate load much higher than the cracking load, mainly in statically indeterminate structures [7-9]. Due to the larger degree of statically indeterminacy of slabs supported on soil, piles, or reinforced concrete columns, they are the type of structural elements where the potentialities of the post-cracking of SFRC can be effectively mobilized in order to practically eliminate the use of conventional reinforcement, as demonstrated elsewhere [10-13], where steel fibre reinforced self-compacting concrete (SFRSCC) was used to build elevated slab systems for residential buildings [12, 13].

Despite the recognized potentialities of SFRC for the enhancement of the sustainability, load carrying capacity, and ductility of slab structural systems [11], the still lack of a well-accepted and relatively simple approach capable of taking into account the post-cracking benefits of SFRC is an obstacle on the design of this type of structural elements, and consequently, on the use of this composite material in certain cases that can constitute cost competitive solutions. Traditional elastic approaches neglect the post-cracking benefits of SFRC leading to underestimations of the load carrying capacity of SFRC slabs. The yield line theory (YLT) [14] has also been used in the design of SFRC slabs supported on soil $[3,15,16]$. This approach provides an upper bound for the loadcarrying capacity of the slab, since an elasto-plastic flexural response is assumed for the slab's cross section. The YLT is consensual when using conventional flexural reinforcement, but the discrete and the "erratic" nature of fibre reinforcement erases some concerns on the use of YLT, unless fibre distribution and orientation are taken into account on the evaluation of the flexural capacity of a SFRC cross section. The post-cracking contribution of SFRC 
is simulated by the tensile stress-crack width $(\sigma-w)$ relationship that can be obtained in direct tensile test (DTT) $[17,18]$ or, alternatively, by using the results of beam bending tests (BBT) [19-21].

Computer programs based on the finite element method have been used to simulate the behaviour of SFRC slabs. These computer programs include constitutive models capable of modelling the nonlinear behaviour of the SFRC, mainly the crack initiation and propagation.

The numerical simulations of experimental tests with this types of SFRC structures have evidenced, however, that for assuring high accurate simulations, the $\sigma-w$ obtained directly from DTT and, indirectly by performing inverse analysis with the BBT, should be altered, mainly the stress at crack initiation and the fracture energy [11]. This is due to the dependency of the post-cracking behaviour of SFRC on the fibre distribution and orientation, as well as on the nature of cracking process, since cracks of several orientations are formed in a slab, while in DTT and BBT a governing crack is formed orthogonally to the axis of the specimen. Therefore, a design methodology for SFRC slab should be based on constitutive models that are representative of the behaviour of the SFRC in this type of structures. For the evaluation of the energy absorption of fibre reinforced concrete (FRC) to be applied in slab and shell type structures, the experts for specialised construction and concrete systems (EFNARC) proposed a test composed of a square panel where its contour is simply supported (SPT-css), and is subjected to a central load [22]. Alternatively, the test composed of a round panel simply supported on its contour (RPT-css) has also been utilized by some authors [12]. Moreover, a statically determinate round panel test, supported in three pivots (RPT-3ps), was recommended in ASTM C-1550 standard [23]. Despite the better representation of the biaxial flexural capacity of SFRC, the SPT-css, RPT-css, or RPT-3ps give no explicit information about the tensile post-cracking response of SFRC, unless a complementary model is utilized, capable to interpret inversely the mechanical properties of the fibrous concrete from the test results.

The existing analytical and numerical models in this respect are scarce, and are often based on the equilibrium of the internal and external work dissipated along predetermined, and often symmetric cracking lines. A simple approach was developed by Marti et al. [24] assuming symmetric crack patterns in the SPT-css and RPT-css, and adopting a predefined stress-crack width relationship of softening character and with parabolic configuration. By using this approach under the framework of the YLT, these authors derived the load deflection curves registered in the aforementioned panels. This approach was adopted by Khaloo and Afshari [25] to develop equations capable of determining the force-deflection response of a square panel supported on its edges. A semi-analytical model was 
also developed by Nour and Massicotte [26] to evaluate the post-cracking behaviour of SFRC from the results of tests with panels simply supported on its four edges. In this approach the SFRC was assumed to have a tension softening behaviour, and the load-deflection response of the panel was determined by the YLT.

The present paper describes an experimental program conducted to evaluate the influence of the tensile postcracking behaviour of SFRC on the load-deflection response of SPT-css. For this purpose, a numerical model is developed that considers work equilibrium conditions and constitutive laws of SFRC in tension and compression, and uses a moment-rotation approach recently proposed [27]. The predictive performance of this model is assessed by simulating the force-deflection response of SPT-css, and RPT-3ps obtained in experimental programs. A parametric study is carried out with this model for assessing the influence of the post-cracking performance of SFRC on the behaviour at serviceability limit conditions, on the load carrying capacity, and on the deformational response of RPT-css.

\section{Experimental program}

\subsection{Compositions and material properties of SFRSCC}

The test program was conducted on samples made by SFRSCC, whose mix design has followed the recommendations presented in [28]: the proportions of the constituent materials of the paste were firstly defined, then the proportions of each aggregate on the final solid skeleton were determined, and finally the paste and solid skeleton were mixed in different proportions until self-compacting requirements are assured in terms of spread ability, correct flow velocity, filling ability, blockage and segregation resistance. Two fibre contents, 45 and 60 $\mathrm{kg} / \mathrm{m}^{3}$, were utilized in the developed SFRSCCs, herein designated by FRC45 and FRC60, respectively. Hooked-end steel fibres were used, characterized by a length of $33 \mathrm{~mm}\left(l_{f}\right)$, a diameter of $0.55 \mathrm{~mm}\left(d_{f}\right)$, an aspect ratio of 60 $\mathrm{mm}\left(l_{f} / d_{f}\right)$, and according to the supplier, a yield stress of about $1300 \mathrm{MPa}$. The compositions of the SFRSCCs are indicated in Table 1. 
Table 1: Compositions of the SFRSCCs used in the experimental program [per $1 \mathrm{~m}^{3}$ ]

\begin{tabular}{lcc}
\hline & FRC45 & FRC60 \\
\cline { 2 - 3 } Material & Mass & Mass \\
& {$[\mathrm{Kg}]$} & {$[\mathrm{Kg}]$} \\
\hline Cement & 401.7 & 413 \\
Water & 117.3 & 128 \\
Super-plasticizer & 7.7 & 7.83 \\
Limestone Filler & 344.3 & 353 \\
Fine river sand & 178.3 & 176.9 \\
Coarse river sand & 688.1 & 644.2 \\
Crushed granite & 600 & 587.5 \\
Fibres & 45 & 60 \\
\hline
\end{tabular}

\subsection{Compressive and tensile strength of the SFRSCCs}

The average values of the compressive $\left(f_{c c}\right)$ and tensile strength $\left(f_{c t}\right)$ of the SFRSCCs are summarized in Table 2. The $f_{c c}$ of the SFRSCCs at 28 days was obtained by performing compression tests with cylinder specimens according to EN 206-1 [29], while the $f_{c t}$ and modulus of elasticity ( $E_{c}$ ) were determined following the recommendations of fib Model Code 2010 [19], hereafter abbreviated by fib MC-2010, by applying Eq. (1) and (2), respectively.

$f_{c t}= \begin{cases}0.30 f_{c c}^{2 / 3} & {[\text { for } \leq C 50 / 60]} \\ 2.12 \ln \left(1+f_{c c} / 10\right) & {[\text { for }>C 50 / 60]}\end{cases}$
$E_{c}=21.5\left(\frac{f_{c c}}{10}\right)^{1 / 3} \quad\left[f_{c c}\right.$ in $\mathrm{MPa}, E_{c}$ in GPa $]$

Table 2: Material properties of the SFRSCCs used in the experimental program

\begin{tabular}{cccc}
\hline \multirow{2}{*}{ SFRSCC } & $f_{c c}$ & $f_{c t}$ & $E_{c}$ \\
& {$[\mathrm{MPa}]$} & {$[\mathrm{MPa}]$} & {$[\mathrm{GPa}]$}
\end{tabular}




\begin{tabular}{llll}
\hline FRC45 & 65.2 & 3.43 & 40.17 \\
FRC60 & 61.9 & 3.27 & 39.48 \\
\hline
\end{tabular}




\subsection{Post-cracking response of the SFRSCCs}

In prismatic elements, like standard beam utilized in the beam bending tests (BBT), fibres are preponderantly aligned with the length of the element due to the wall effects, while in the slabs and shell type elements fibres have a tendency to be orthogonally to the SFRSCC flux lines, mainly when fibre concrete has a pronounced selfcompacting character [30]. Therefore, BBT conduct, in general, to a post-cracking residual strength higher than the one registered in specimens with the crack plane orthogonal to the SFRSCC flow direction in a slab, leading to unsafe design predictions. By extracting cylinder cores from a slab prototype and executing on the corresponding double edge wedge splitting type of test (DEWST) [31] notches of different orientation in respect to the SFRSCC flow direction, stress-crack width relationship representative of the SFRSCC in the real application can be obtained. Furthermore, due to the heaviest mass density of steel fibres amongst the constituents of a SFRSCC, steel fibres have a tendency to sink along the depth of the element, in the casting direction [32]. By obtaining the DEWST specimens from slicing at different depth of the cylinder cores extracted from a slab prototype [16], the influence on the stress-crack width of the fibre distribution in the depth of the slab can be captured, which provides reliable information for layered modelling approaches $[3,6]$.

Therefore, in the present study, the post-cracking response of the SFRSCCs was characterized by executing DEWST [31] conducted on samples extracted from the intact regions of the "mother" tested panels. A special device was used to assure a "V" shape notch of mutually orthogonal surfaces (Fig. 1a), where the longitudinal axis of the "V channel" coincides with the casting direction (Fig. 1a). Furthermore, to favour the crack propagation along the plan formed by the apex of the $\mathrm{V}$ notches, vertical notches with a depth of $10 \mathrm{~mm}$ and a width of $5 \mathrm{~mm}$ were executed over the width of the specimen at the apex of each "V" notch (Fig. 1b).

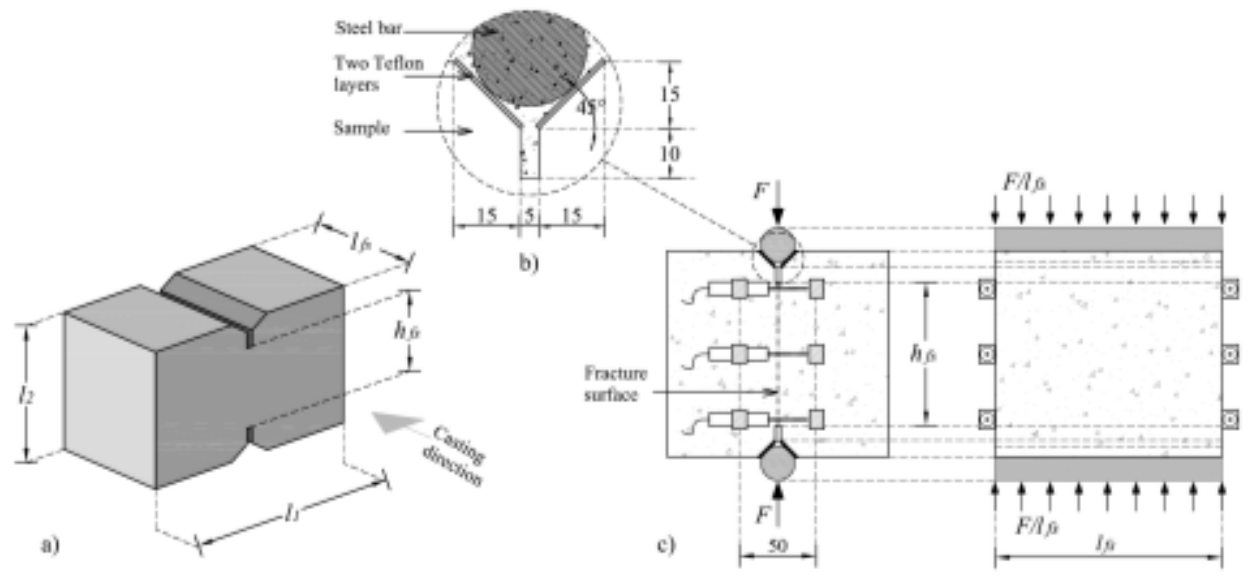


Fig. 1: Details of the double edge wedge splitting test; a) sample shape, b) geometry of the "V" notch, c) test setup (dimensions in $\mathrm{mm}$ ).

The set-up of the DEWST is depicted in Fig. 1c, where the compressive force, applied by a hydraulic actuator of 100 $\mathrm{kN}$ capacity, was introduced to the specimen by means of a pair of steel bars of $30 \mathrm{~mm}$ diameter, laid into the top and bottom "V" notches (Figs. 1b and 1c). This configuration induces the formation of a governing crack in the notched plane (designated by "Fracture surface" in Fig. 1c), due to the development of a tensile stress field with principal tensile stresses preponderantly orthogonal to this plane. Therefore, the orientation of this crack in the DEWST is the same of the flexural cracks in the corresponding performed SPT. However, the cracking evolution process in both cases are different, since for the DEWST it is expected an almost constant crack width in the fracture surface during the loading process (plane stress state), while in the SPT the crack opening has an almost linear profile along the depth of the panel due to the flexural nature of these cracks. Adopting a measurement length of 50 $\mathrm{mm}$, the average crack mouth opening displacements (CMOD) were obtained from the six displacement transducers (LVDTs) mounted on front and rear faces of the samples, as depicted in Fig. 1c. The test procedure was controlled by the actuator's internal LVDT, at a displacement rate of $0.2 \mathrm{~mm} / \mathrm{min}$. The transverse tensile stress along the fracture surface was obtained indirectly from the applied compressive load $(F)$ through the following equation [31]: $\sigma_{t}=\eta \frac{F}{h_{f s} \cdot l_{f s}}$

where $h_{f s}$ and $l_{f s}$ are the height and length of the fracture surface (see Fig. 1a), and $\eta$ is a reduction factor that depends on the angle of the "V" notch and on the concrete-steel bar frictional coefficient [31]. To assess the value of $\eta$ parameter, the average stress-CMOD relationship of the DEWST was compared with that obtained from direct tensile tests (DTT) in a research program conducted in parallel to the present study where the same test apparatus was used. These results are compared in Fig. 2, where a $\eta$ parameter value of 0.9 was considered for taking into account the effect of the right angle of the "V" notch and the two lubricated Teflon layers applied between steel bars and concrete (see Fig. 1b). 


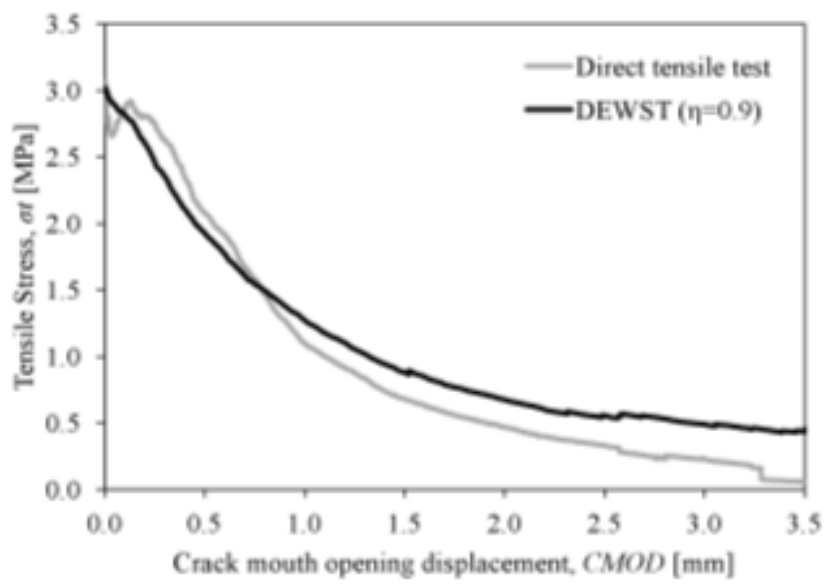

Fig. 2: Comparison between stress-CMOD relationship of DTT and DEWST.

The post-cracking response of FRC45 and FRC60 in terms of tensile stress-crack mouth opening displacement, abbreviated hereafter by stress-crack width relationship, is shown in Fig. 3a and 3b, respectively, where the envelope represents the scatter of the six DEWST samples extracted from each series of the square panels. The envelope indicates the maximum and the minimum of the entity represented in the ordinate axis for each value of the entity represented in the abscissa axis. This approach is applied to the envelope concept of all the figures presented in this paper.

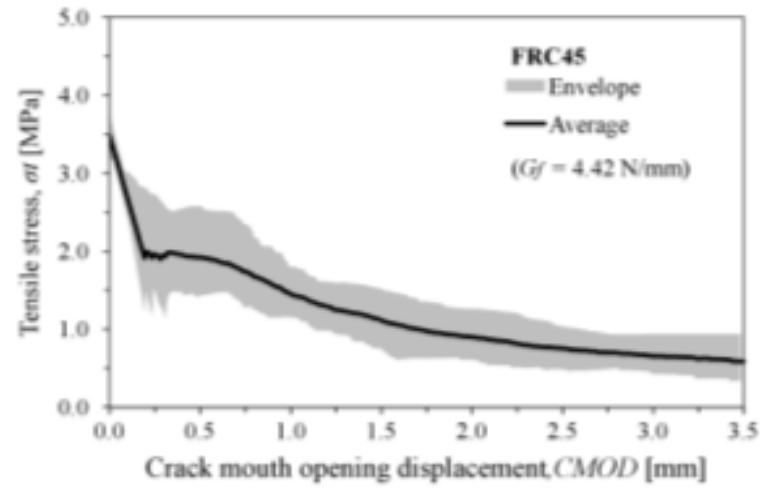

a)

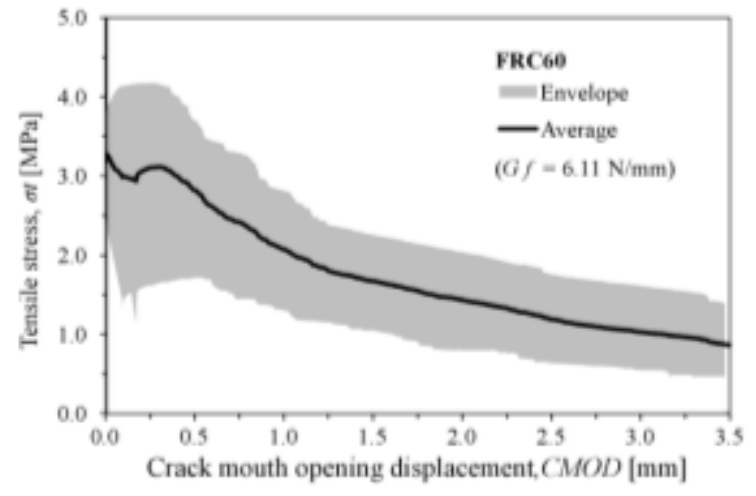

b)

Fig. 3: Envelope and average tensile stress-CMOD relationship of the DEWST: a) FRC45, b) FRC60. 
As expected, the energy absorption during the fracture process ( $G_{f}-$ area under the stress-CMOD relationship) was higher in FRC60 due to the larger content of fibres utilized. Up to a CMOD of $3.5 \mathrm{~mm}$, the $G_{f}$ of FRC60 was $40 \%$ higher than the one of the FRC45.

\subsection{Square panel test with continuous simply support (SPT-css)}

\subsubsection{Geometry and test setup}

The test program with SPT-css comprised two series of six square panels with dimensions of $600 \times 600 \times 100 \mathrm{~mm}^{3}$ that were built with FRC45 and FRC60 compositions, designated as SP45 and SP60, respectively. By following the EFNARC specifications [22], the square panels were tested according to the test setup represented in Fig. 4, where the panel is simply supported on its contour with a clear span length of $500 \mathrm{~mm}$ in each direction, subjected to a central load distributed via a $100 \times 100 \times 25 \mathrm{~mm}^{3}$ steel plate. The load was applied by a hydraulic actuator of 250 $\mathrm{kN}$ capacity, and was measured by a load cell of $200 \mathrm{kN}$ capacity. The test was displacement controlled by using a LVDT of $50 \mathrm{~mm}$ gauge length that measured the vertical deflection of the loading plate. The imposed deflection rate was $0.25 \mathrm{~mm} / \mathrm{min}$ up to $0.5 \mathrm{~mm}$, and $1.0 \mathrm{~mm} / \mathrm{min}$ up to attain $25 \mathrm{~mm}$ deflection in the centre of the panel [22]. 


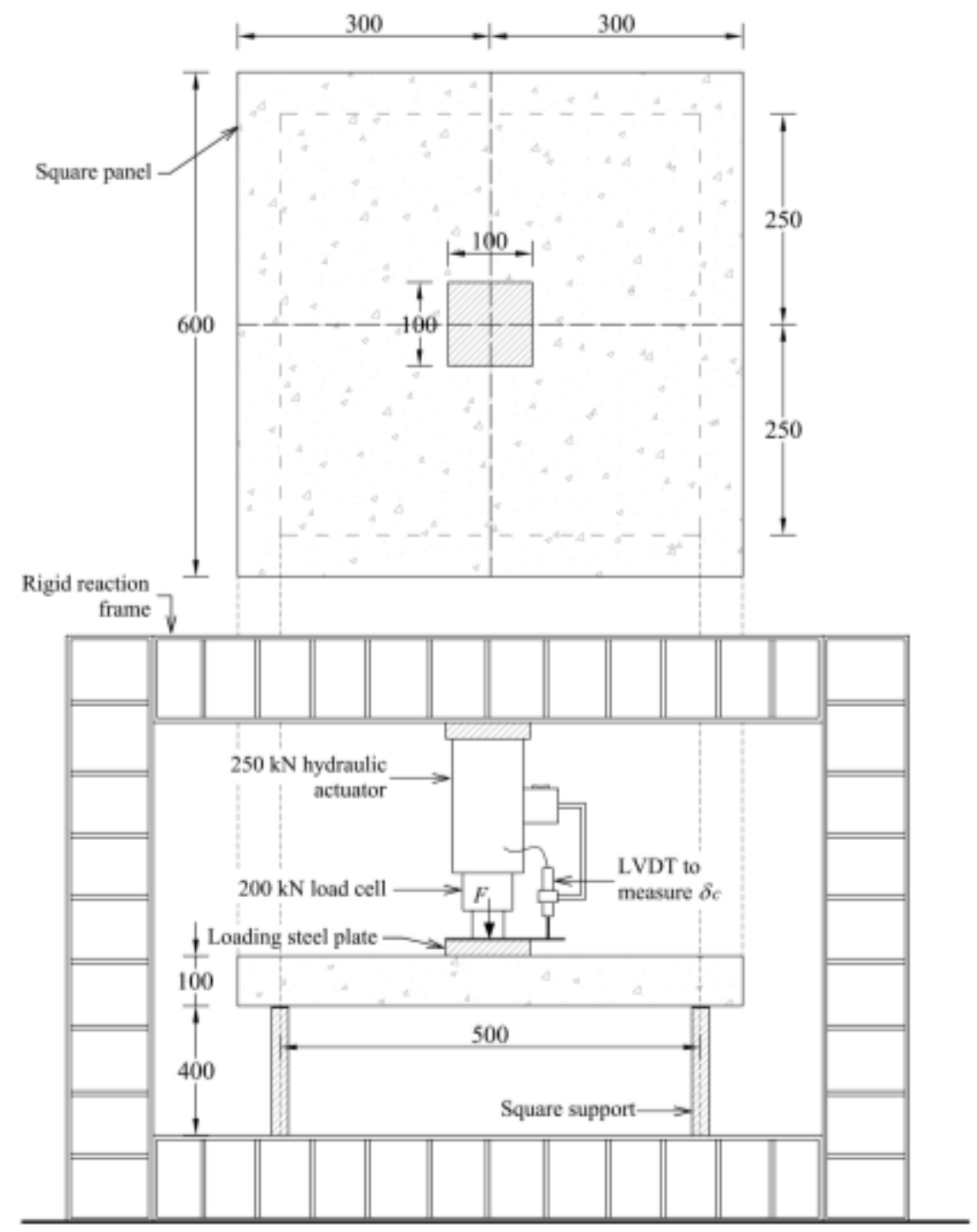

Fig. 4: Test setup of the SPT-css (dimensions in mm).

\subsubsection{The SPT-css results and analysis}

The panels failed predominantly in flexure with the crack patterns represented in Fig. 5, without a noticeable influence of the content of fibres in this respect. Apart the SP45-5 and SP60-5, and also the SP60-6 that include 5 and 6 cracks, respectively, four dominant cracks were formed. 


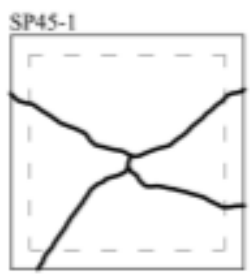

SP45-3

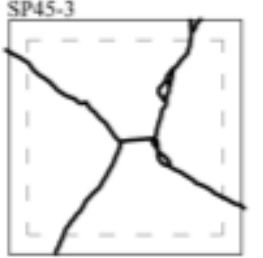

SP45-5
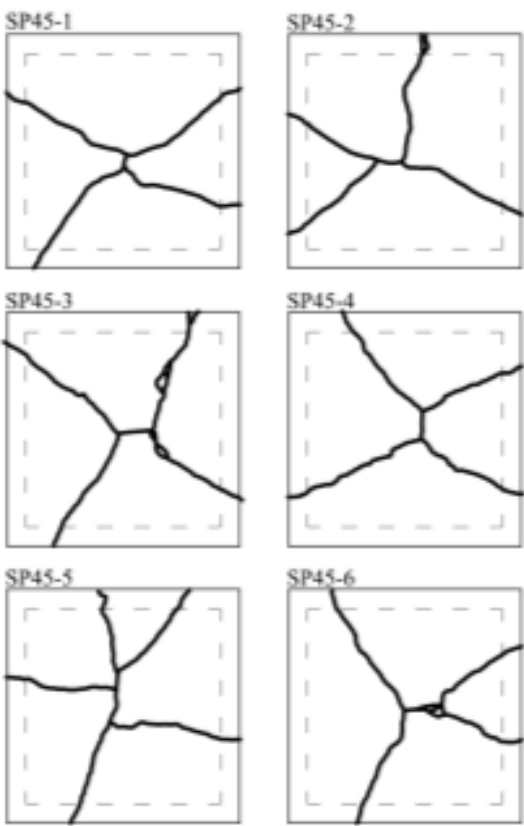

a)
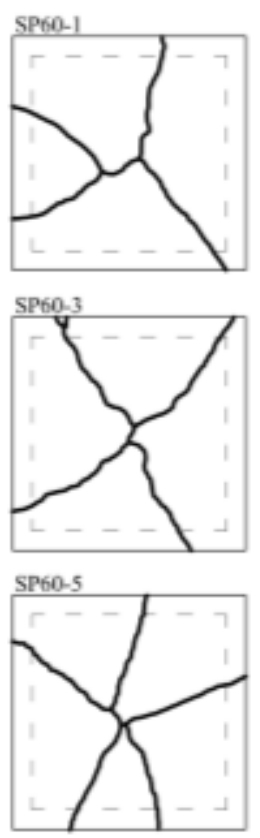

b)
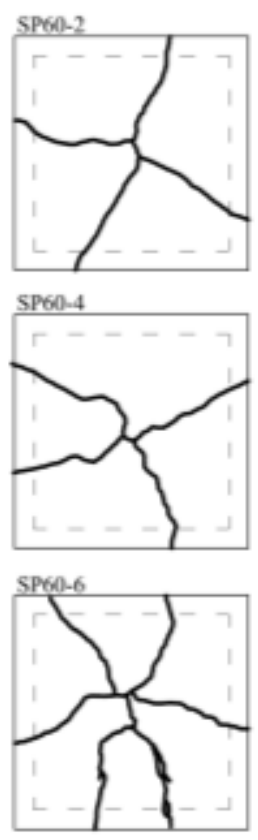

Fig. 5: Ultimate crack patterns of the square panels of series: a) SP45, b) SP60.

The different crack patterns observed in some panels is due to the fact that the fibre dispersion and orientation have erratic nature, which is very sensitive to the casting procedure [33]. The formation of larger number of cracks in some of the panels is justified by a larger number of fibres or/and a better orientation of fibres bridging the four primary formed cracks.

Fig 5 also reveals the formation of four diagonal cracks in SPT-css assumed by the YLT [14] was not verified in this experimental program, since almost all tested panels include cracks that intersect the edges of the panel, leading to pseudo-yield lines of smaller length than the ones considered in the YLT. In consequence, the YLT may overestimate the load carrying capacity of this type of panels. It should be noted that in the context of the YLT applied to FRC structures, a crack is assumed as a pseudo-yield line due to the relatively high post-cracking flexural resistance of FRC. Bjøntegaard [34] has determined experimentally the influence of the support-friction conditions on the behaviour of SPT-css, by comparing the force $v s$. central deflection relationship $\left(F-\delta_{c}\right)$ obtained from SPTcss and from SPT with a frictionless test setup assured by using two layers of plastic sheet with grease for the interface between the support and the panel. This study revealed an average reduction of $15 \%$ and $46 \%$ of the peak load and the residual load at $25 \mathrm{~mm}$ deflection, respectively, when support-friction was eliminated in the test [34]. 
This reduction was considered on the evaluation of the envelope and on the average of the force versus central deflection $\left(F-\delta_{c}\right)$ of SPT-css represented in Fig. 6, in order to exclude the effect of friction on the obtained results.

This was executed by updating the magnitude of the force recorded experimentally $\left(F_{\text {exp }}\right)$ according to the following equation:

$F= \begin{cases}0.85 F_{\text {exp }} & \delta_{c} \leq \delta_{c}^{F_{\max }} \\ {\left[0.85-0.0124\left(\delta_{c}-\delta_{c}^{F_{\max }}\right)\right] F_{\text {exp }}} & \delta_{c}>\delta_{c}^{F_{\max }}\end{cases}$

where $F_{\max }$ is the peak load and $\delta_{c}^{F_{\max }}$ is the panel central deflection corresponding to $F_{\max }$.

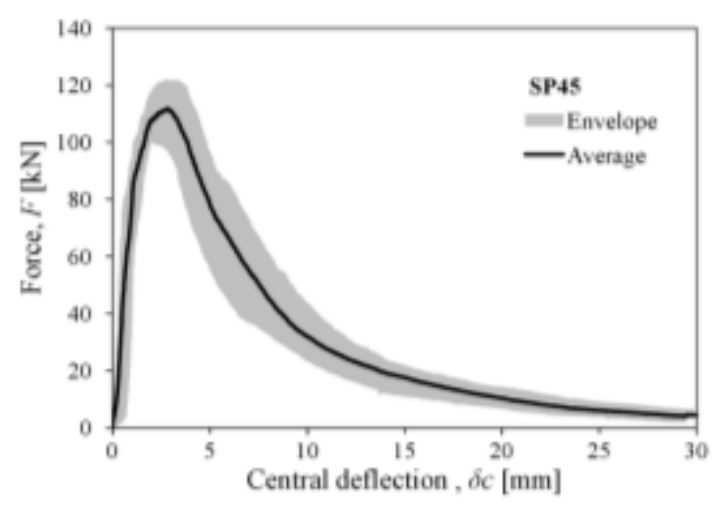

a)

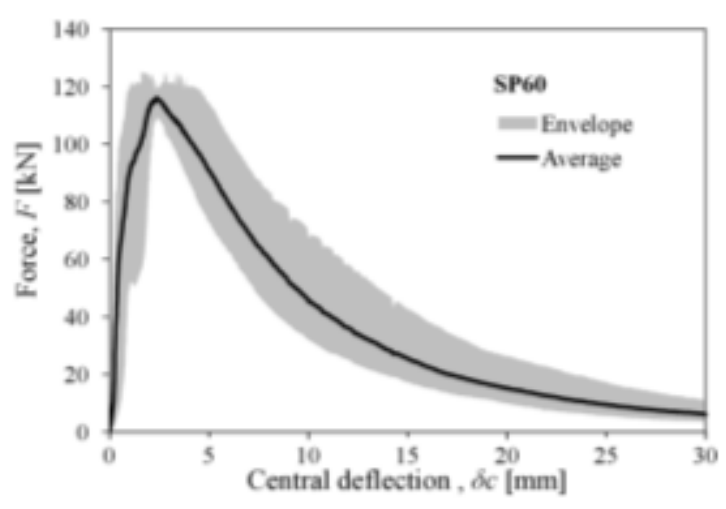

b)

Fig. 6: Force-central deflection of SPT-css in series: a) SP45, and b) SP60.

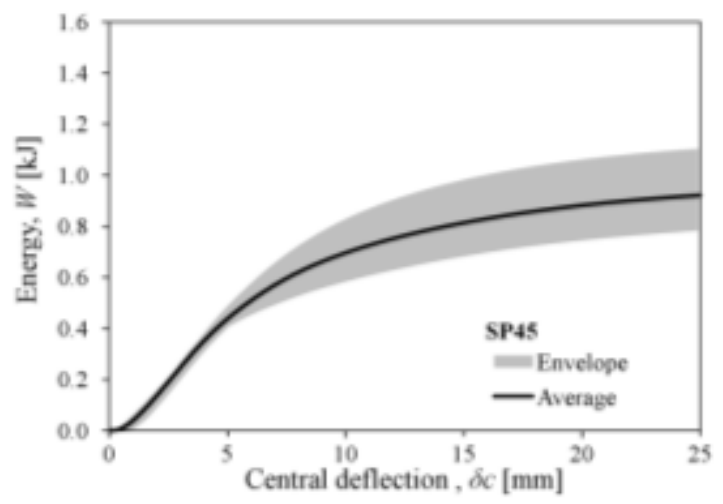

a)

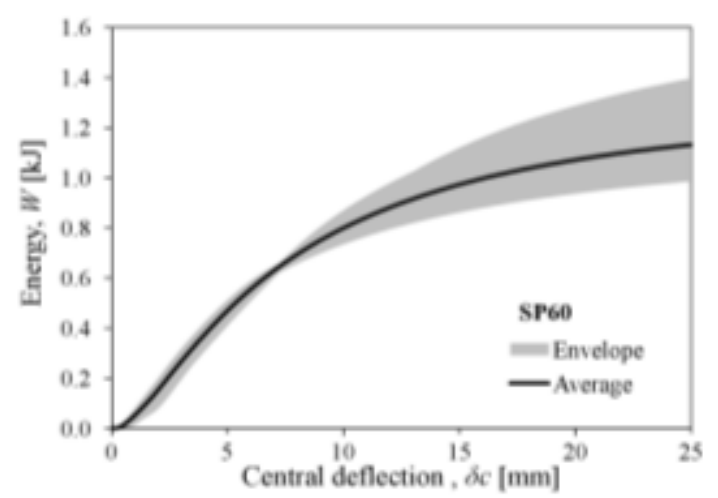

b)

Fig. 7: Energy absorption vs. central deflection of SPT-css in series: a) SP45, and b) SP60. 
The energy absorption versus central deflection $\left(W-\delta_{c}\right)$ in the SPT-css is represented in Fig. 7, where the $W_{\delta_{c}}$ was determined by integrating the $F-\delta_{c}$ curve according to the following equation:

$$
W_{\delta_{c}}=\int_{0}^{\delta_{c}} F . d \delta_{c}
$$

\section{Development of numerical model}

To have an explicit representation of the influence of the tensile post-cracking response of FRC on the load carrying capacity of SPT-css, RPT-css, and RPT-3ps, a numerical model was developed by using a moment-rotation approach [27] and virtual work method. This model can be applied to any type of FRC, as long as the constitutive laws of the FRC are known, mainly its stress-crack width relationship.

\subsection{Constitutive laws of FRC}

\subsubsection{Compressive behaviour}

Regarding to the dominant intervening mechanisms, the compressive response of FRC can be subdivided into two distinct stages: the pre-peak and the post-peak region. Until the peak load, only small isolated and randomly distributed cracks exist in the volume of the material, and the distribution of stresses and strains can be reasonability predicted by continuous mechanics. Therefore the pre-peak compressive behaviour of FRC is characterized by the stress-strain law $\left(\sigma_{c c}-\varepsilon_{c c}\right)$ schematized in Fig. 8a, whose equation was proposed by Vipulanandan and Paul [35], and later modified by Barros and Figueiras [36] for SFRC reinforced with hooked-end fibres:

$$
\begin{aligned}
& \sigma_{c c}\left(\varepsilon_{c c}\right)=f_{c c} \frac{\varepsilon_{c c} / \varepsilon_{c c, p}}{(1-p-q)+q\left(\varepsilon_{c c} / \varepsilon_{c c, p}\right)+p\left(\varepsilon_{c c} / \varepsilon_{c c, p}\right)^{\frac{1-q}{p}}} \\
& \left.q=1-p-\frac{E_{c, \mathrm{sec}}}{E_{c}}, p+q \in\right] 0,1\left[, \frac{1-q}{p}>0\right.
\end{aligned}
$$

where $\varepsilon_{c c, p}$ is the strain corresponding to the concrete compressive strength $\left(f_{c c}\right)$ obtained from the following equation:

$$
\varepsilon_{c c, p}=\varepsilon_{c c, p}^{P C}+0.0002 W_{f}
$$




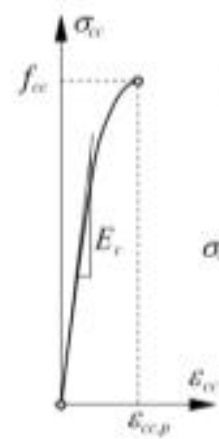

a)

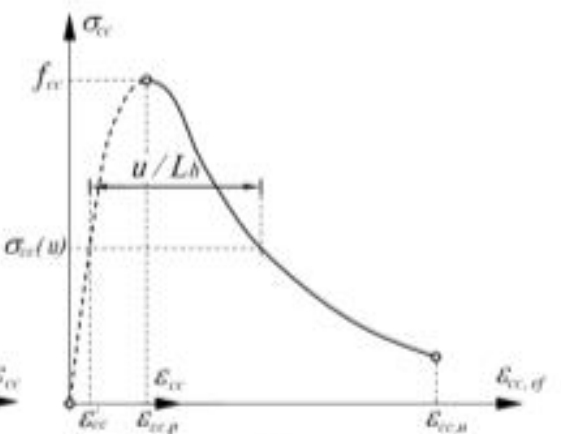

b)

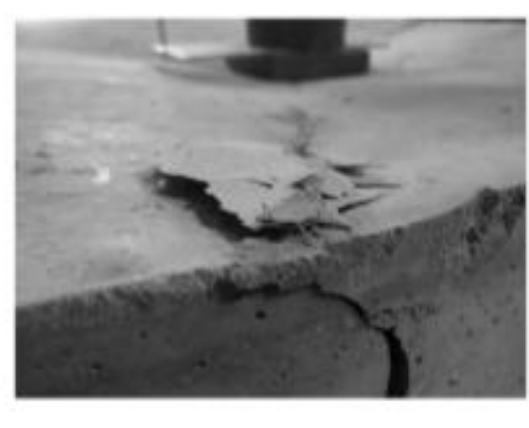

c)

Fig. 8: Compressive behaviour of a FRC: a) pre-peak stress-strain response, b) post-peak stress-deformation response, c) sliding of a concrete wedge along radial crack on the top compressed face of a panel.

where $W_{f}$ is the fibre weight percentage, and $\varepsilon_{c c, p}^{P C}$ is the strain at compressive strength of the plain concrete of the same strength class of FRC [19]. In Eq. (7) $E_{c, \text { sec }}$ is the secant modulus of elasticity of concrete $\left(=f_{c c} / \varepsilon_{c c, p}\right)$, and $E_{c}$ is the Young's modulus determined from Eq. (2). Moreover, $p$ is a parameter ranging between 0 and 1 that can be obtained from the following equation:

$p=1.0-0.919 \exp \left(-0.394 W_{f}\right)$

If hooked ends steel fibres is not the reinforcement system, equations (8) and (9) should be calibrated since they were determined for concrete reinforced with this type of fibres.

After the peak load, an increase of the deformation leads to the subsequent coalescence of internal cracks into major cracks where the damage is localized. This invalidates the use of strain as state variable in constitutive laws for concrete [37], and since the localized damage band can be physically simulated by a crack, the fracture mechanics should be used to describe the failure of concrete. When concrete enters in its post-peak stage, the compressive behaviour is simulated by the stress versus effective strain $\left(\varepsilon_{c c, e f}=\varepsilon_{c c}^{\prime}+u / L_{h}\right)$ diagram schematically depicted in Fig. 8b. The compressive behaviour at this stage is governed by the shear sliding of a concrete wedge in the compression zone, as depicted in Fig. 8c. 
Fig. 9a represents schematically the formation of a concrete wedge shear sliding in the compression zone of a FRC element subjected to pure bending, $M$, and corresponding rotation of $\theta$ of the extremities. In Fig. 9a is also considered an equal spacing of $L_{h}$ for the flexural cracks formed along the beam length. A concrete elementary volume of a length of $L_{h} / 2$ crossed by the shear band zone is represented in Fig. 9b. The stress and displacement components acting in this shear band zone are depicted in Fig. 9c, where $\tau_{1}$ and $\sigma_{1}$ represent the shear and the compressive stress, respectively.

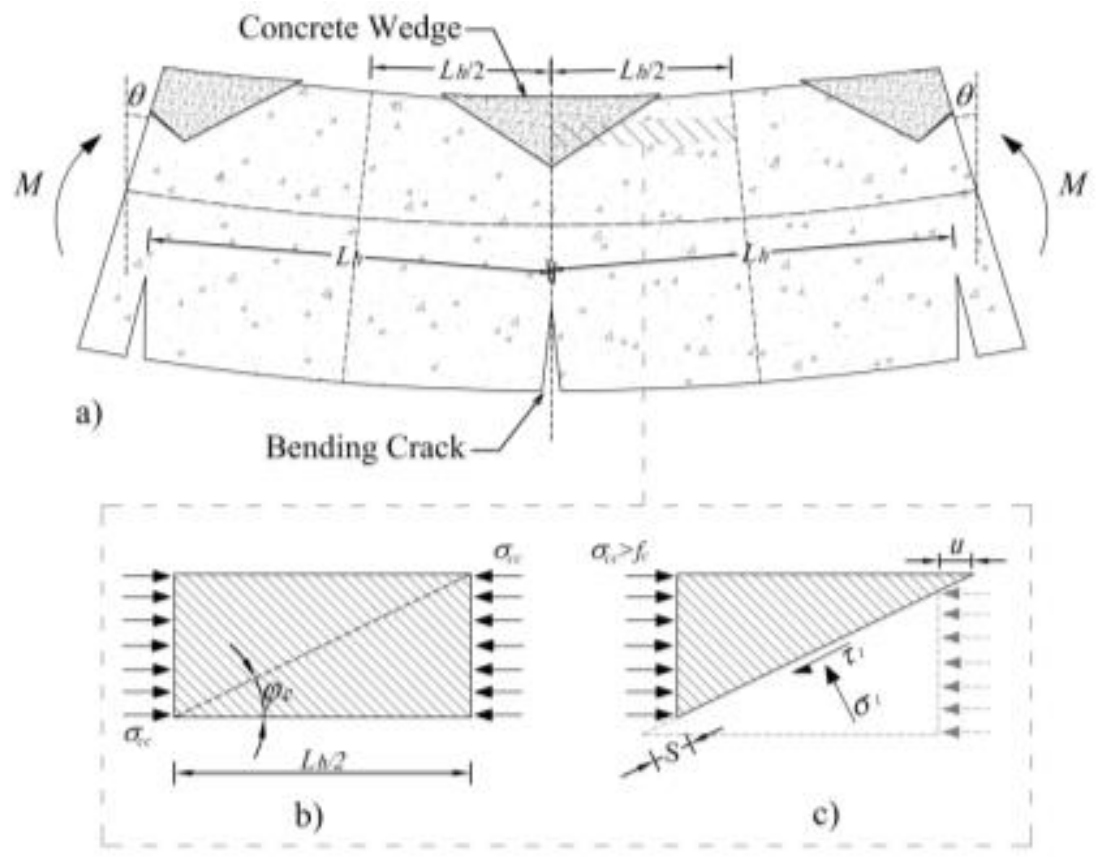

Fig. 9: a) Concrete wedge shear sliding in the compression zone of a bending element, b) concrete element under compression, c) stresses and displacement of the wedge.

Due to the softening nature of the variation of $\tau_{1}$ and $\sigma_{1}$ with the increase of shear sliding in a shear bands [38], the compressive stress in the concrete also decreases with the increase of the sliding $(S)$. The shear stress in the shear band can be correlated to the axial displacement of the wedged concrete by the following equation [39]:

$\tau_{1}=0.497 f_{c c}+\left(-30.142+51.623 \frac{\sigma_{1}}{f_{c c}}\right)\left(\frac{u}{\cos \varphi_{c}}\right)\left(\frac{f_{c c}}{30}\right)^{0.91} \quad[\mathrm{~N}, \mathrm{~mm}]$ 
where $\varphi_{c}$ is the concrete frictional angle, which can be assumed equal to $37^{\circ}$ for ordinary concrete, and $u$ is the horizontal component of sliding $(S)$ of the concrete wedge in compression softening (Fig. 9c). Imposing equilibrium equations in both horizontal and vertical directions of the forces acting on the concrete wedge of Fig. 9c, the following equation is derived for determining the concrete compressive stress for the sliding displacement $u$ in the post peak stage of the compression behaviour:

$\sigma_{c c}(u)=\frac{2}{\sin \left(2 \varphi_{c}\right)}\left(\frac{-30.142\left(\frac{u}{\cos \left(\varphi_{c}\right)}\right)\left(\frac{f_{c c}}{30}\right)^{0.91}+0.497 f_{c c}}{1-51.623\left(\frac{\sin \left(\varphi_{c}\right)}{f_{c c}}\right)\left(\frac{u}{\cos ^{2}\left(\varphi_{c}\right)}\right)\left(\frac{f_{c c}}{30}\right)^{0.91}}\right) \quad[\mathrm{N}, \mathrm{mm}]$

More detailed information in this respect can be found elsewhere [27].

\subsubsection{Tensile behaviour}

The tensile behaviour of FRC is decomposed in pre-cracking and post-cracking phases. The pre-cracking response of FRC is simulated by a linear stress-strain response (Fig. 10a):

$\sigma_{c t}\left(\varepsilon_{c t}\right)=E_{c} \varepsilon_{c t} \quad\left(0 \leq \varepsilon_{c t} \leq \varepsilon_{c r}\right)$

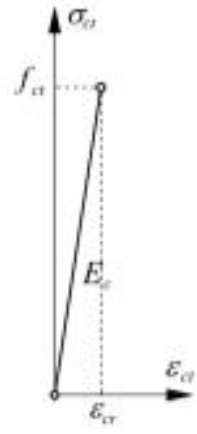

a)

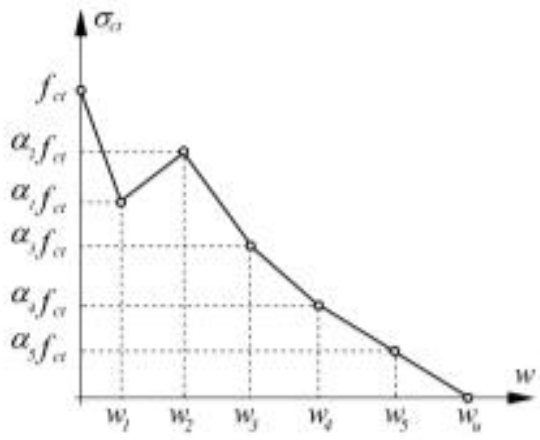

b)

Fig. 10: Tensile behaviour of a FRC: a) stress-strain pre-peak response, b) post-peak stress-crack width response.

where $\varepsilon_{c r}=f_{c t} / E_{c}$ is the strain at crack initiation, and $f_{c t}$ is the tensile strength that can be obtained from Eq. (1). The post-cracking response of FRC is simulated by a stress-crack opening diagram that can be formed by multilinear segments (Fig. 10b) in order to have the potential of capturing, with high accuracy, the behaviour of strain softening and strain hardening FRCs [40]: 


$$
\begin{aligned}
& \sigma_{c t}(w)=\left[\alpha_{m}+\left(\alpha_{m+1}-\alpha_{m}\right) \frac{w-w_{m}}{w_{m+1}-w_{m}}\right] f_{c t} \quad\left(w_{m}<w \leq w_{m+1}\right) \\
& {\left[m=0 \text { to } 6, \alpha_{0}=1, w_{0}=0, \alpha_{6}=0, w_{6}=w_{u}\right]}
\end{aligned}
$$

where $\alpha_{m}=\sigma_{m} / f_{c t}$ is the normalized stress parameter corresponding to the crack width $w_{m}$, and $w_{u}$ is the ultimate crack width considered for the FRC.

\subsection{Cinematic assumptions}

In the proposed model it is assumed that in SPT-css, RPT-css and RPT-3ps, just after the peak load, dominant cracks propagate in the panel according to a general asymmetric crack pattern. For the sake of simplicity, it is assumed that the cracks are straight and radiate from the centre of the panel (point $C$ in Fig. 11) with random orientation. In the particular case of the SPT-css, the cracks have different length, in agreement to the test results (see Fig. 11).
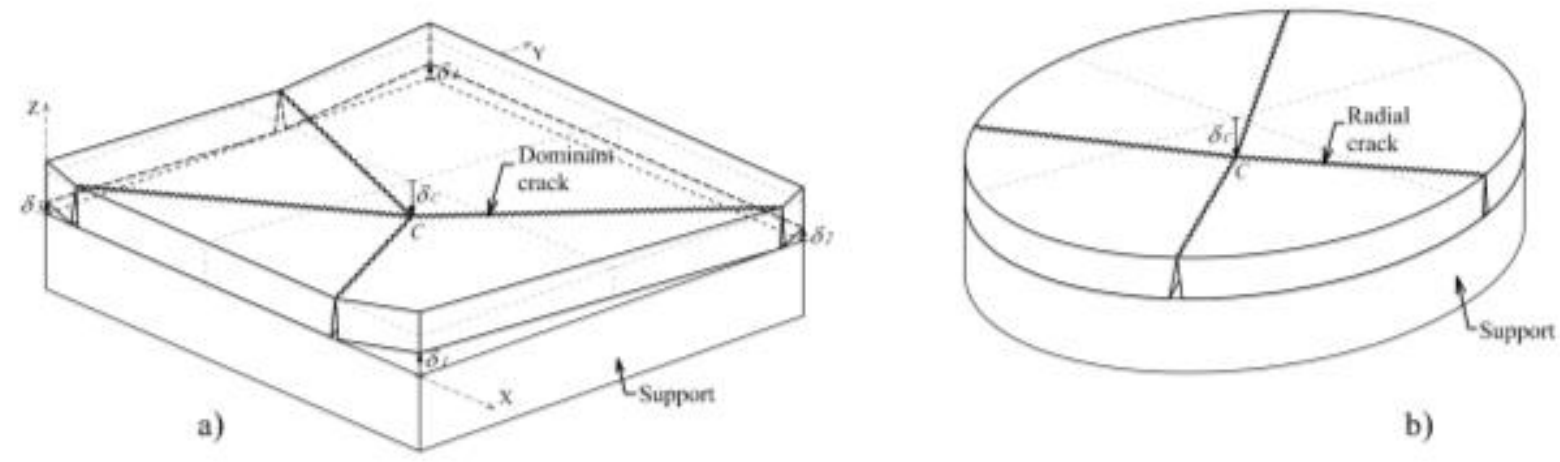

b)

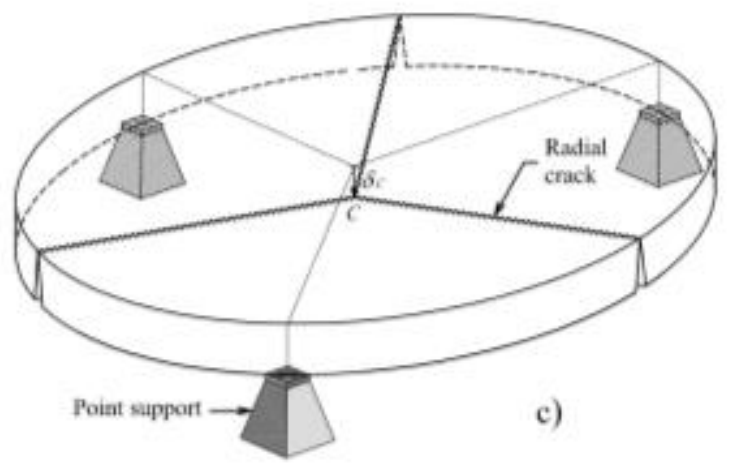

Fig. 11: Crack pattern and deformation of panel in: a) SPT-css, b) RPT-css, and c) RPT-3ps.

In Figs. 11a and 11b are schematized the considered deflection configuration for SPT-css and RPT-css, respectively, where the propagation of $n_{c r}$ cracks subdivides the panels into $n_{c r}$ intact (un-cracked) plates, whose elastic 
deformation is recovered in the structural softening stage when cracks are opening gradually. Since this elastic deformation is much lower than the deflection due to crack opening, it can be neglected, and the vertical deformation of the panel's centre (point C) is caused by the rigid rotation of the plates in turn of their connecting dominant cracks.

It is notable that, due to asymmetry of the crack patterns often observed in SPT-css and RPT-css, rotation of the rigid plates, in general, does not necessarily take place around the support line as observed at initial test conditions. In fact, in a SPT-css (or RPT-css), the panel contour has a tendency to move upward, losing the initial contact between panel and supporting system (Figs. 11 and 12).

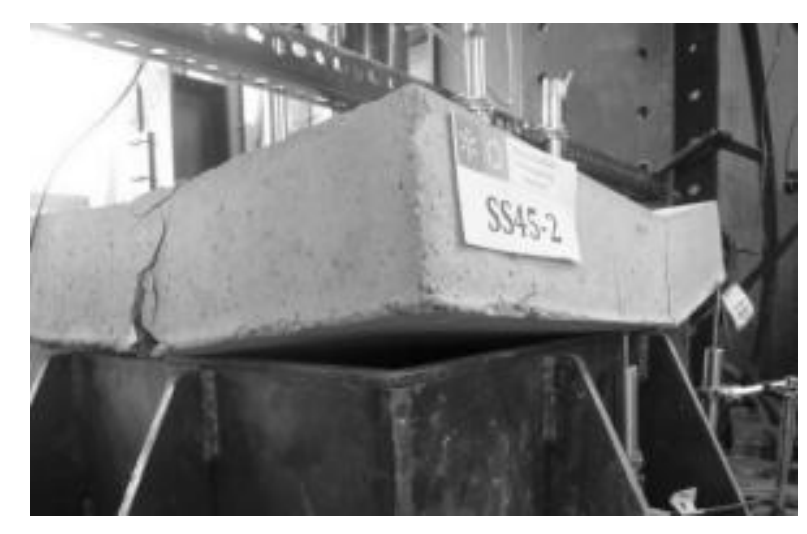

Fig. 12: Upward deflection of slab with respect to support line.

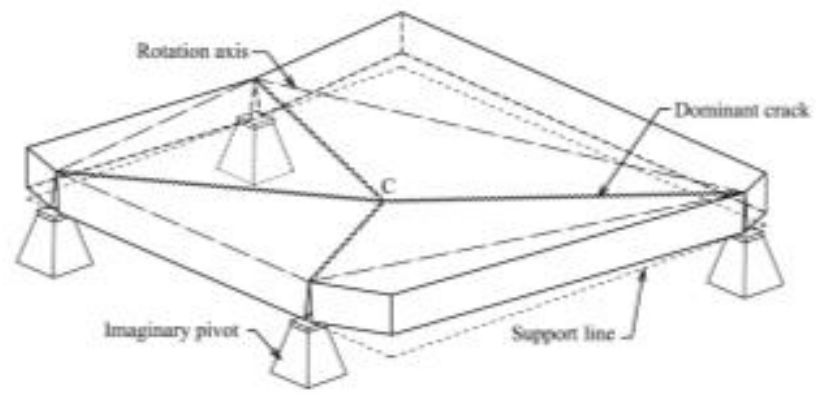

a)

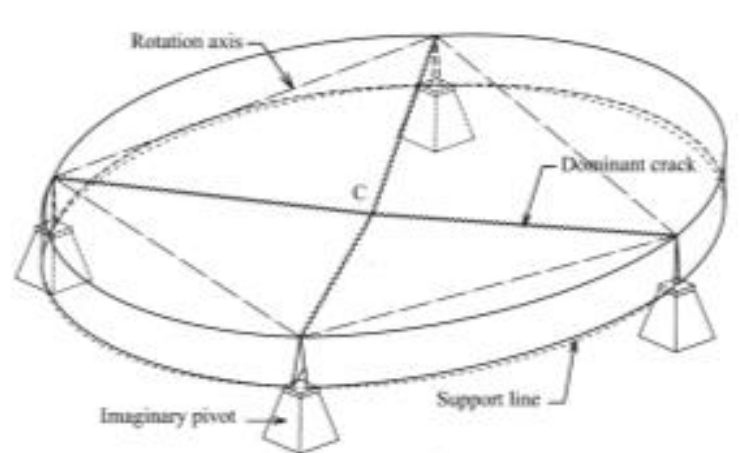

b)

Fig. 13: Representation of imaginary pivots and rotational axes of uncracked plates in: a) SPT-css, and b) RPT-css. 
In this case the panel keeps resting on the points located at the intersection of the radial cracks with the support line, herein designated by imaginary pivots, as schematized in Fig. 13. The rotational axis of each rigid plate is considered the line drawn between two pivots supporting the plate, as indicated by the dotted lines in Fig. 13.

In Fig. 14a is schematized the $i^{\text {th }}$ crack and its two contiguous rigid plates, designated by plate 1 and plate 2, respectively, in a SPT-css. The overall rotation of the $i^{\text {th }}$ crack is the result of the rigid rotation of the adjacent plates around their own axes. Taking a normal to the alignment of the $i^{\text {th }}$ crack from the mid-point of the rotation axes of the panels 1 and 2, point $A_{i, 1}$ and $A_{i, 2}$, its intersection with the $i^{\text {th }}$ crack gives the points $B_{i, 1}$ and $B_{i, 2}$, respectively (Fig. 14b).

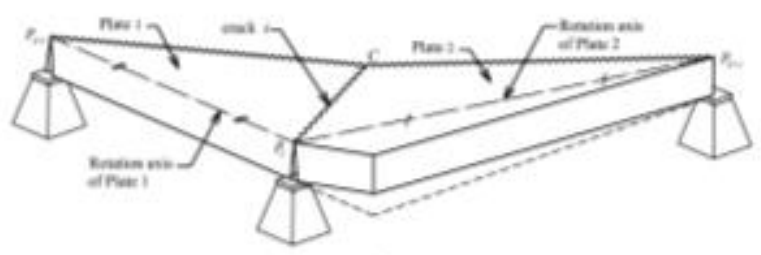

a)

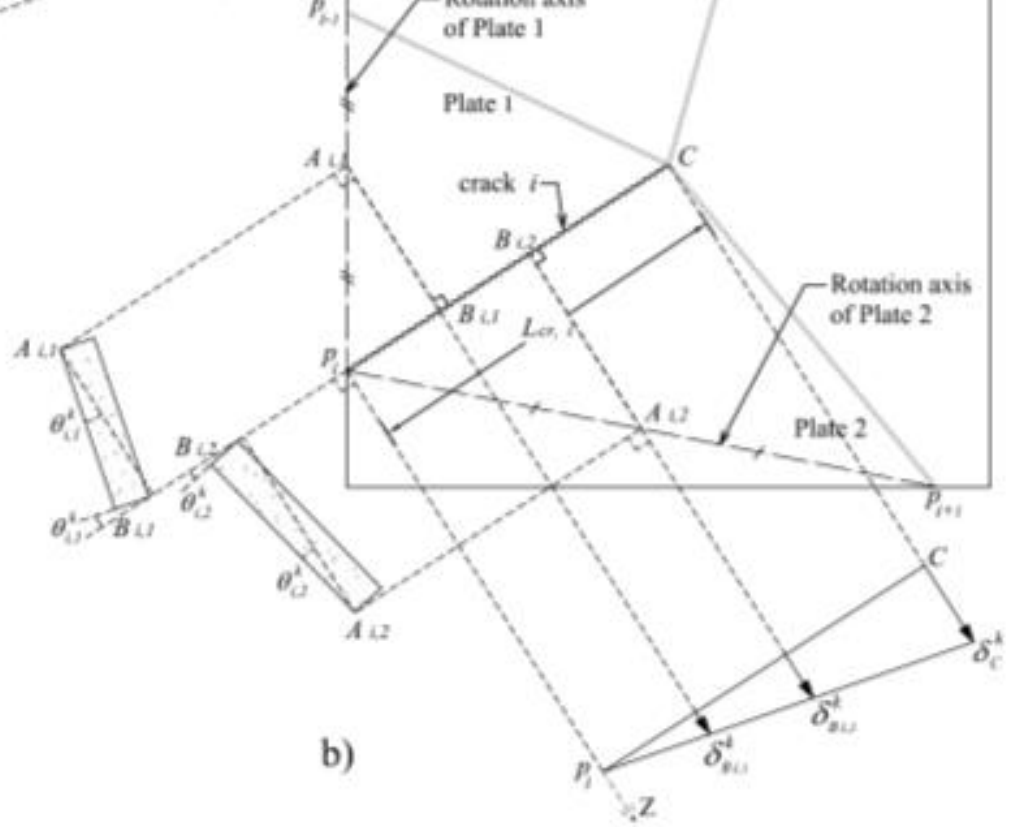

Fig. 14: a) Rigid rotation of intact plates in SPT-css, and b) crack rotation analysis in SPT-css.

Assuming a linear variation of vertical deflection along the crack and considering zero deflection at the pivot of the $i^{\text {th }}$ crack ( $p_{i}$ in Fig. 14b), the deflection of points $B_{i, 1}$ and $B_{i, 2}$ can be determined from the deflection occurred in the centre of the panel in the $k^{\text {th }}$ step of loading $\left(\delta_{c}^{k}\right)$ : 
$\delta_{B_{i, 1}}^{k}=\left(\frac{B_{i, 1} p_{i}}{C p_{i}}\right) \delta_{c}^{k}$

$\delta_{B_{i, 2}}^{k}=\left(\frac{B_{i, 2} p_{i}}{C p_{i}}\right) \delta_{c}^{k}$

The $\delta_{c}^{k}$ is assumed linearly dependent of the incremental central deflection $\left(\Delta \delta_{c}\right)$ adopted in the computation $\left(\delta_{c}^{k}=k \Delta \delta_{c}\right)$. The deflections $\delta_{B_{i, 1}}^{k}$ and $\delta_{B_{i, 2}}^{k}$ impose, respectively, the rotations $\theta_{i, 1}^{k}$ and $\theta_{i, 2}^{k}$, as depicted in Fig. 14b, determined by the following equations:

$$
\begin{gathered}
\theta_{i, 1}^{k}=\frac{\delta_{B_{i, 1}}^{k}}{A_{i, 1} B_{i, 1}} \\
\theta_{i, 2}^{k}=\frac{\delta_{B_{i, 2}}^{k}}{A_{i, 2} B_{i, 2}}
\end{gathered}
$$

By adding the rotations of the plates connecting the $i^{\text {th }}$ crack, it is obtained the rotation of this crack due to the imposed deflection $\delta_{c}^{k}$ at the panel centre:

$$
\theta_{i}^{k}=\theta_{i, 1}^{k}+\theta_{i, 2}^{k}
$$

In case of RPT-3ps, due to its statically determinate nature, three radial cracks often propagate between the point supports and, therefore, the round panel is subdivided in three rigid plates. The rotation axes of the plates in the RPT-3ps are the lines drawn tangent to the slab perimeter at each point support and intersect mutually at the assumed imaginary point located in the alignment of the median crack (Fig. 15). 


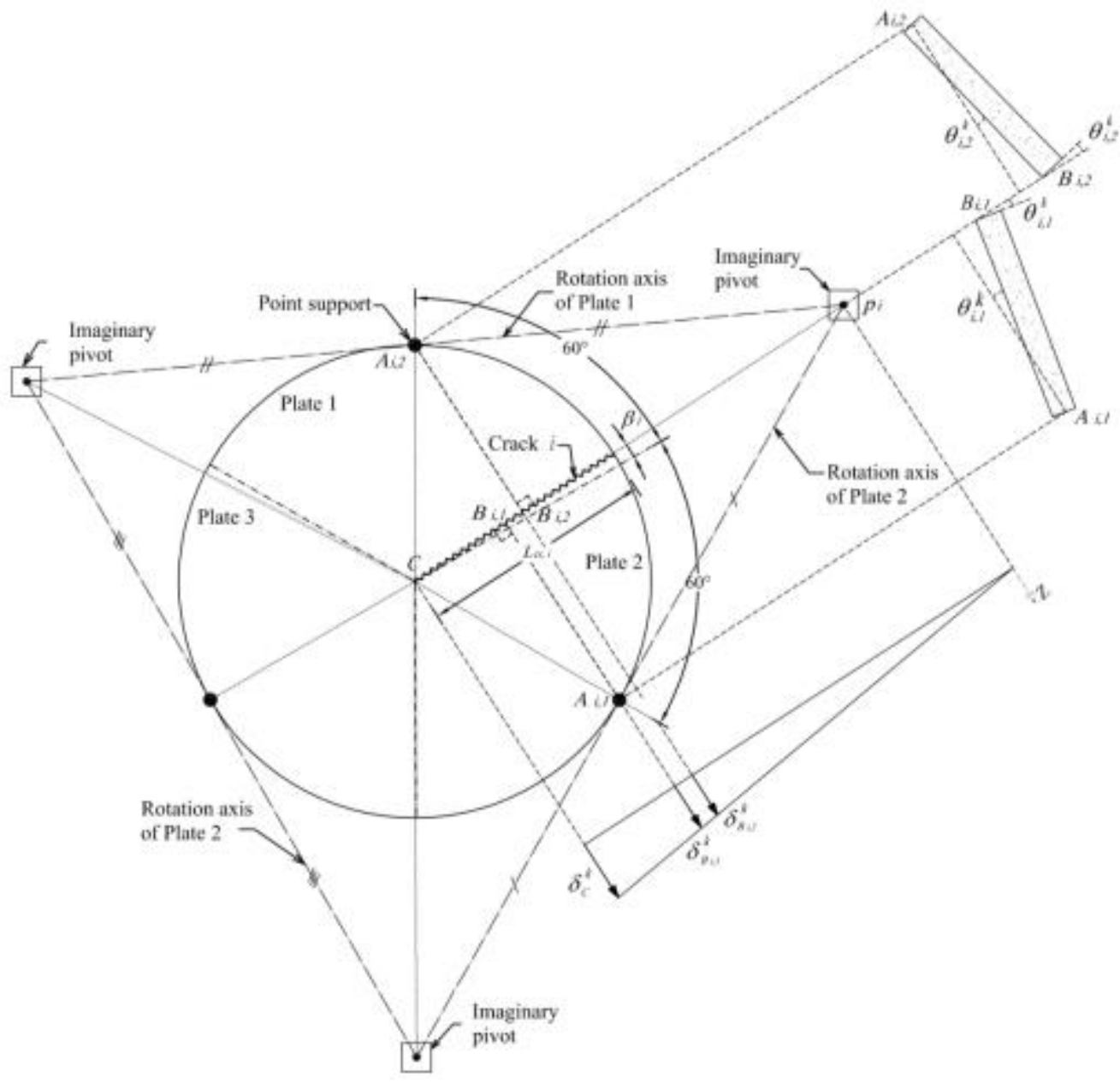

Fig. 15: Crack rotation analysis in RPT-3ps.

In the RPT-3ps the alignment of a radial crack in each sector of the panel, between two consecutive point supports, can have a certain deviation with respect to the line bisecting that sector (represented by dotted lines in Fig. 15). Considering this type of misalignment for the $i^{\text {th }}$ crack, represented by $\beta_{i}$ in Fig. 15, the two corresponding rotational arms $\left(A_{i, 1} B_{i, 1}\right.$ and $\left.A_{i, 2} B_{i, 2}\right)$ intersect the crack alignment in two distinct points: $B_{i, 1}$ and $B_{i, 2}$. The resisting bending moment per unit width of the slab section corresponding to the imposed $\theta_{i}^{k}, M_{i}^{k}$, is determined from the model proposed by Taheri and Barros [27]. 


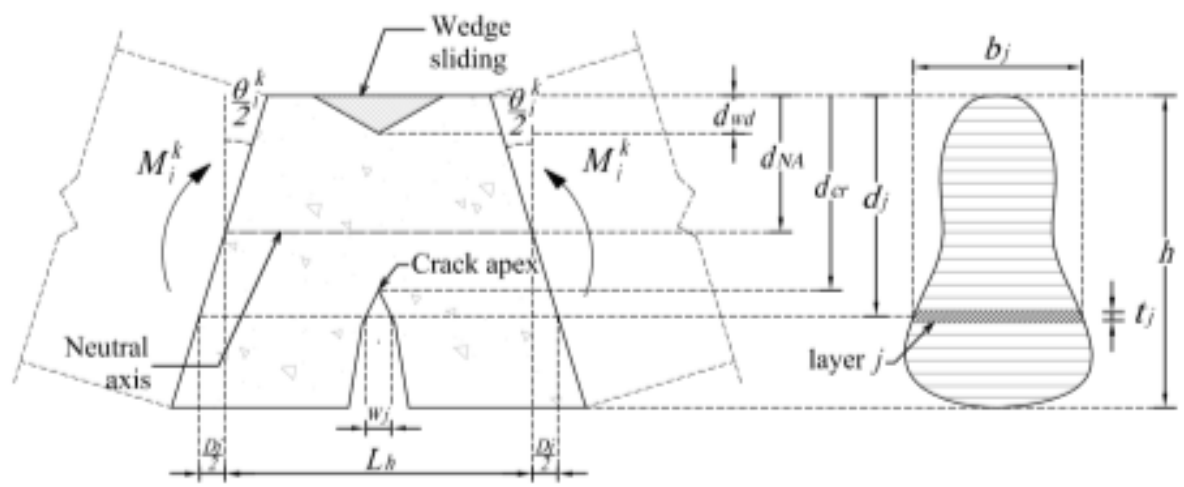

a)

b)

Fig. 16: a) Cracked FRC segment of length submitted to pure bending, and b) layer approach to discretize the cross section.

Fig. 16 shows a segment of a FRC beam of a length $L_{h}$ that represents the distance of two consecutive flexural cracks. For FRC elements without conventional flexural reinforcement, fib MC-2010 [19] recommends $L_{h}=h(=$ thickness of the element's cross section). This segment of beam is assumed subjected to a bending moment $M_{i}^{k}$ and correspondent overall rotation $\theta_{i}^{k}$. The cross section is discretized in $n$ layers, and is assumed symmetric. For a wide applicability of the model, the cross section can have a width that varies along its depth. The width, the thickness and the depth of the $j^{\text {th }}$ layer (with respect to the top surface of the cross section) is designated by, respectively, $b_{j}, t_{j}$, and $d_{j}$ (Fig. 16b). For the sake of simplicity of the notation, the superscript $k$ representing the load step of the panel will not be used in the symbols of the layer model for the evaluation of the moment-rotation relationship of the cross section.

For each value of $\theta_{i}^{k}$ resultant from the imposed central deflection (Eq. 18), the axial displacement of the $j^{\text {th }}$ layer, $D_{j}$, is determined by considering its position $\left(d_{j}\right)$ and the depth of the neutral axis $\left(d_{N A}\right)$ :

$D_{j}=\theta_{i}^{k}\left|d_{j}-d_{N A}\right|$

Accordingly, the effective strain of the $j^{\text {th }}$ layer is obtained from the following equation:

$\varepsilon_{e f, j}=\frac{D_{j}}{L_{h}}$

The compressive force of the layer, whose $d_{j}<d_{N A}$, can be obtained from the following equation: 
$F_{j}= \begin{cases}\sigma_{c c}\left(\varepsilon_{e f, j}\right) b_{j} t_{j} & \text { if } \varepsilon_{e f, j} \leq \varepsilon_{c c, p} \\ \sigma_{c c}\left(u_{j}\right) b_{j} t_{j} & \text { if } \varepsilon_{e f, j}>\varepsilon_{c c, p}\end{cases}$

where $\sigma_{c c}$ is the compressive stress of the FRC that can be determined from Eqs. (6) and (11), and $u_{j}$ is determined by solving iteratively the following system of equations [27]:

$$
\left\{\begin{array}{l}
\varepsilon_{e f, j}-\varepsilon_{c c, j}^{\prime}-\left(u_{j} / L_{h}\right)=0 \\
\sigma_{c c}\left(u_{j}\right)-\sigma_{c c}\left(\varepsilon_{c c, j}^{\prime}\right)=0
\end{array}\right.
$$

where $\varepsilon_{c c, j}^{\prime}$ is the pre-peak compressive strain of the layer subjected to the axial displacement $u_{j}$ (see Fig. 8b). The internal force of the tension layers $\left(d_{j} \geq d_{N A}\right)$ is obtained from the following equation:

$$
F_{j}= \begin{cases}\sigma_{c t}\left(\varepsilon_{e f, j}\right) b_{j} t_{j} & \text { if } \varepsilon_{e f, j} \leq \varepsilon_{c r} \\ \sigma_{c t}\left(w_{j}\right) b_{j} t_{j} & \text { if } \varepsilon_{e f, j}>\varepsilon_{c r}\end{cases}
$$

being $w_{j}$ the crack width determined by solving iteratively the following equation [27]:

$$
w_{j}=\left[D_{j}-\frac{\sigma_{c t}\left(w_{j}\right)}{E_{c}} L_{h}\right]
$$

where $\sigma_{c t}$ is the post-cracking tensile stress of FRC obtained from Eq. (13). The depth of the neutral axis, $d_{N A}$, is determined by satisfying the equilibrium of internal forces of the layers of the section $\left(\sum_{j=1}^{n} F_{j}=0\right)$. After the equilibrium has been assured, the bending moment of the unit width of the panel corresponding to the applied $\theta_{i}^{k}$ can be evaluated from the following equation:

$$
M_{i}^{k}=\sum_{i=1}^{n} F_{j} d_{j}
$$

By applying the principle of the virtual work, the deflection of the central point of the panel for the $k^{\text {th }}$ loading step is obtained from the following equation:

$$
F_{c}^{k}=\frac{1}{\delta_{c}^{k}} \sum_{i=1}^{n_{c r}}\left(M_{i}^{k} \times L_{c r, i}\right) \theta_{i}^{k}
$$


where $L_{c r, i}$ represents the length of the $i^{\text {th }}$ crack. The flowchart of the algorithm adopted in the proposed model is described in Fig. 17.

(1) Taking the imposed $\theta_{i}^{i}$ as input data

(2) Reading input data including:

- Constitutive laws: $\sigma_{r}(\varepsilon), \alpha_{v}(u), \sigma_{s}\left(\varepsilon_{u}\right), \sigma_{n}(w)$

- Goometry of panel

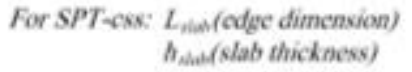

- Goometry of crack puttem:n, $A_{1}, A_{2}, B_{l}, B_{2}, A_{1} L_{i n}$

Loop of increment of $k$

(3) Determination of $\delta_{q}^{t}\left(=k \Delta \delta_{f}\right)$

Loop of increment of i

(4) Determination of $\delta_{n, d}^{t}$ and $\delta_{m, 2}^{t}$ (from Eq. 14 and 15 , respectively)

(5) Determination of $\theta_{i}^{2}$ and $\theta_{1}^{2}$ (from $\mathrm{Eq}, 16$ and 17 , respectively)

(6) Determination of $\theta_{i}^{\lambda}$ (from Eq. 18)

(24) Determination of $F_{e}^{i}$ (from Eq. 26)

i. End of loop

(25) Storage $F_{f}^{t}$ and $\delta_{f}^{t}$

E... End of loop
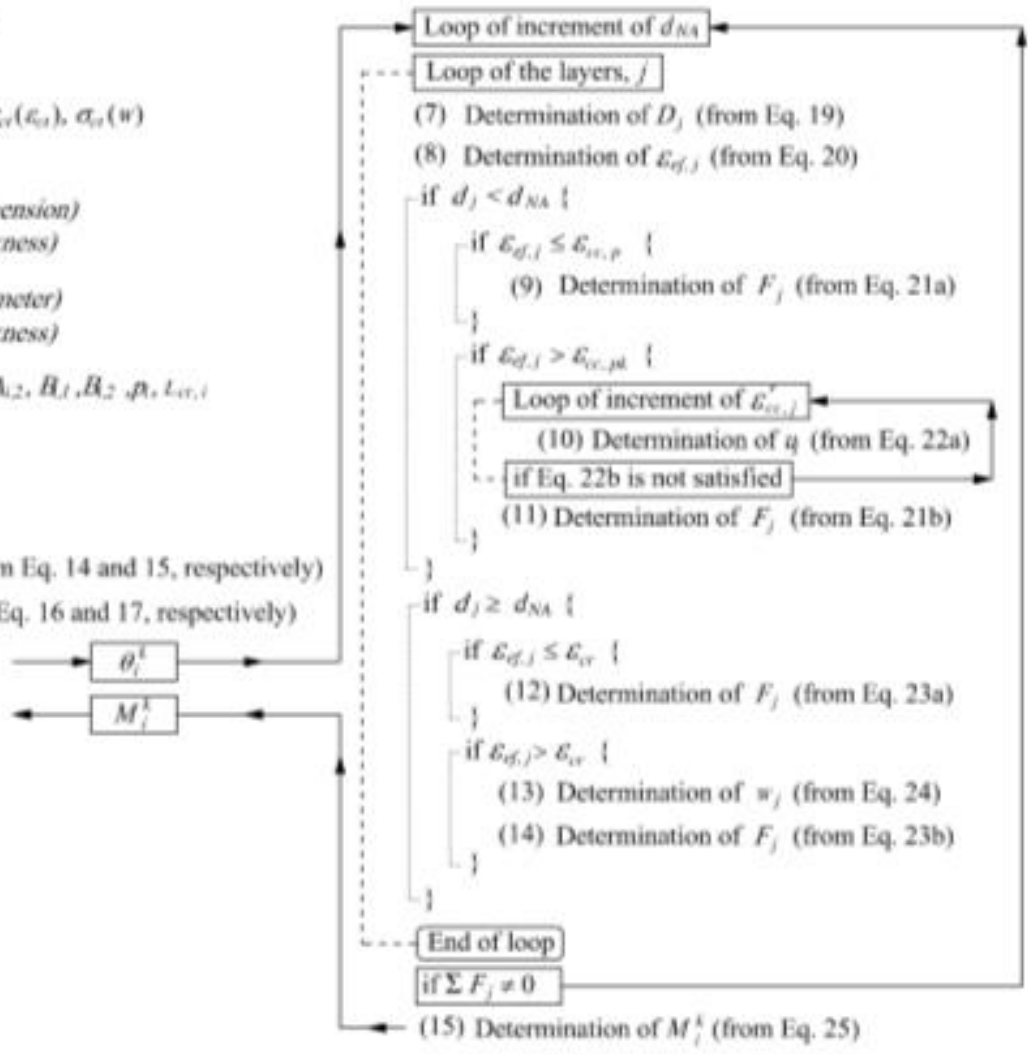

Fig. 17: Flowchart of the algorithm adopted in the developed model.

\subsection{Assessment of the predictive performance of the proposed model}

The predictive performance of the proposed model for SPT-css was assessed by simulating the tests described in Section 2. For this purpose, the crack patterns registered experimentally (Fig. 5) were approached by straight crack lines radiating from the centre of the panels (Fig. 18), in accordance to the assumption adopted in the model. 

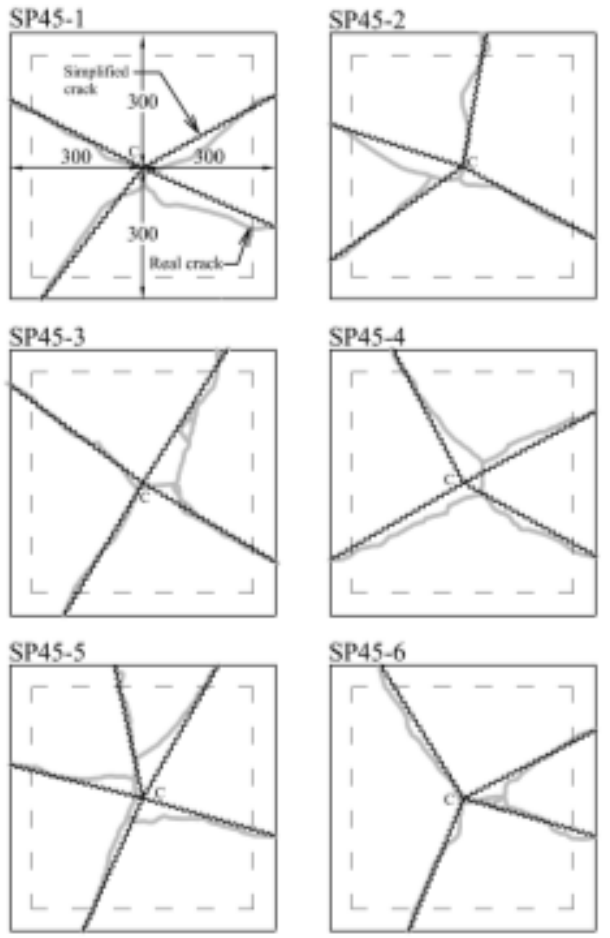

a)
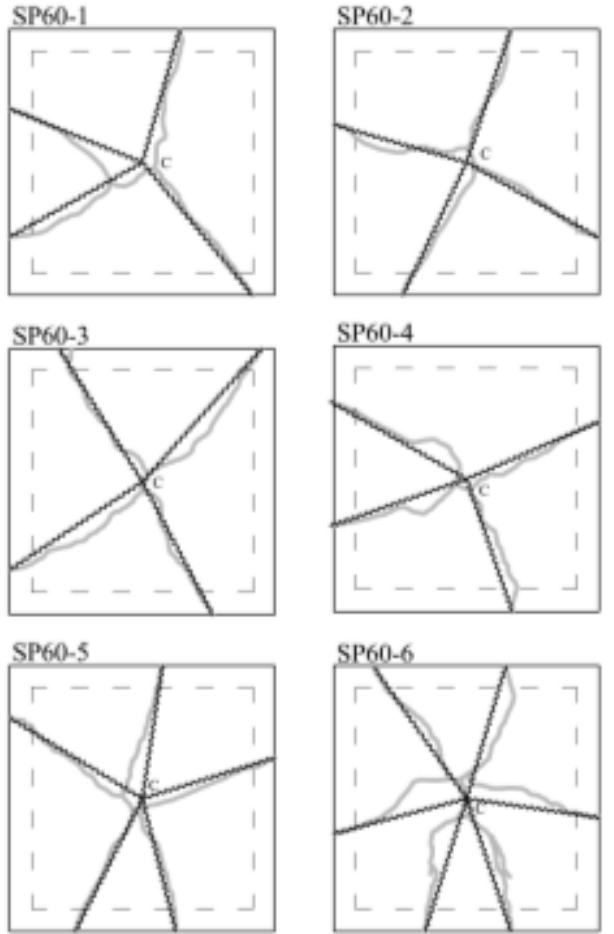

b)

Fig. 18: Crack patterns registered experimentally (grey colour) and considered for the simulations (straight black lines) in: a) SP45, and b) SP60.

For the compressive strength and the Young's modulus of FRC45 and FRC60 the values indicated in Table 1 were considered, while the stress-crack width response of FRC45 and FRC60 was obtained by DEWST, by adopting the multi-linear diagram represented in Fig. 19a, whose defining parameters are summarized in Table 3. By adopting the tensile constitutive laws of the FRCs (Fig. 19a), the moment-rotation response of the unit width of square panels made with FRC45 and FRC60 (i.e. SP45 and SP60, respectively) was determined from the proposed algorithm as depicted in Fig. 19b.

Table 3: Parameters defining the stress-crack width diagrams (Figs. 10 and 19a) obtained from DEWST

\begin{tabular}{ccccccccccccc}
\hline FRC & $\begin{array}{c}f_{c t} \\
{[\mathrm{MPa}]}\end{array}$ & $\alpha_{1}$ & $\alpha_{2}$ & $\alpha_{3}$ & $\alpha_{4}$ & $\alpha_{5}$ & $w_{1}$ & $w_{2}$ & $w_{3}$ & $w_{4}$ & $w_{5}$ & $w_{u}$ \\
\hline FRC45 & 3.43 & 0.55 & 0.57 & 0.51 & 0.36 & 0.26 & 0.20 & 0.40 & 0.75 & 1.20 & 2.00 & 5.00 \\
\hline
\end{tabular}


$\begin{array}{lllllllllllll}\text { FRC60 } & 3.27 & 0.89 & 0.96 & 0.61 & 0.50 & 0.37 & 0.01 & 0.15 & 0.30 & 1.00 & 1.50 & 5.00\end{array}$ 


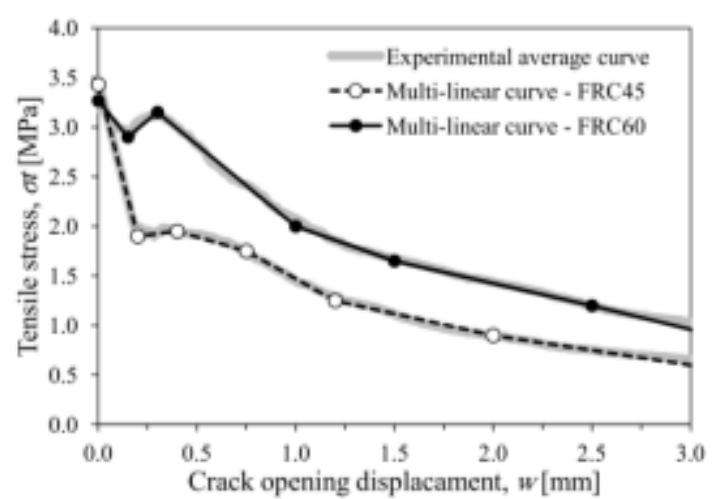

a)

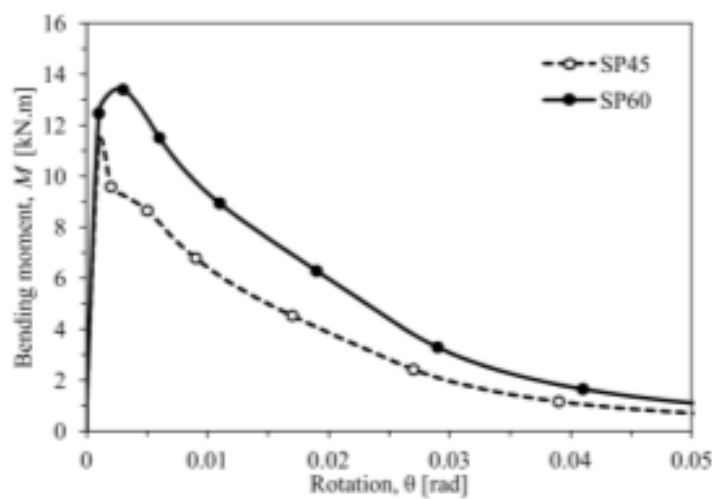

b)

Fig. 19: a) Multi-linear post-cracking response of the FRCs, b) Moment-rotation response of a cross section of unit width of a square panel made with FRC45 and FRC60.

The relationship between the applied force and the post-peak central deflection obtained experimentally and that predicted by the model are compared in Fig. 20a and 20b for the SP45 and SP60 series, respectively. For the experimental results it is represented the average curve, while for the model application it is depicted the envelope of the simulations carried out by considering the cracking patterns of the panels (Fig. 18). A good agreement is observed between the model and the experimental results. According to Fig. 20b larger scatter of the forcedeflection response was obtained in case of SP60 series because four, five and six dominant cracks were considered in the simulations for taking into account the crack patterns registered experimentally. In case of SP45 series a negligible scatter of the results was obtained because apart panel SP45-5, four cracks were formed.

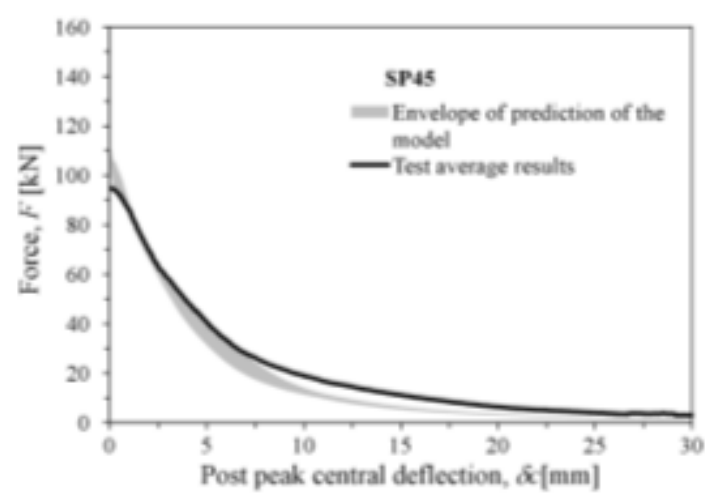

a)

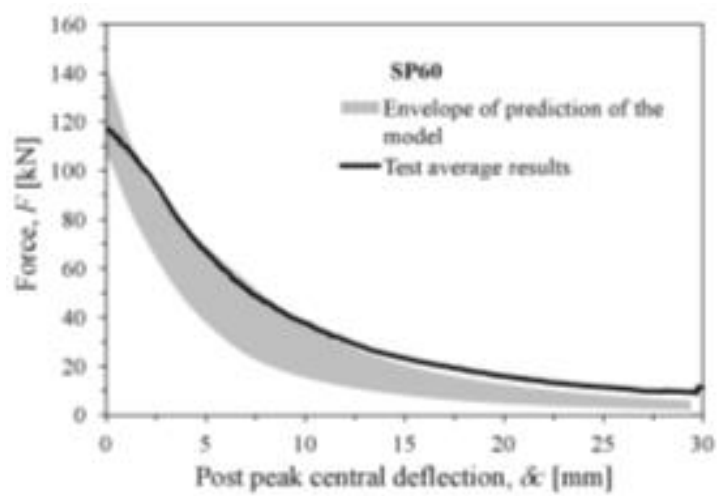

b)

Fig. 20: Relationship between load and the deflection after crack initiation (average experimental results and envelope of the model's prediction) in SPT-css tests of series: a) SP45, and b) SP60. 


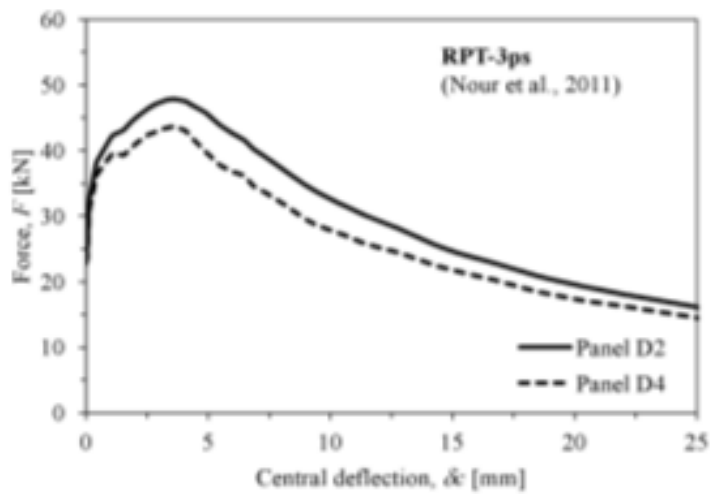

a)

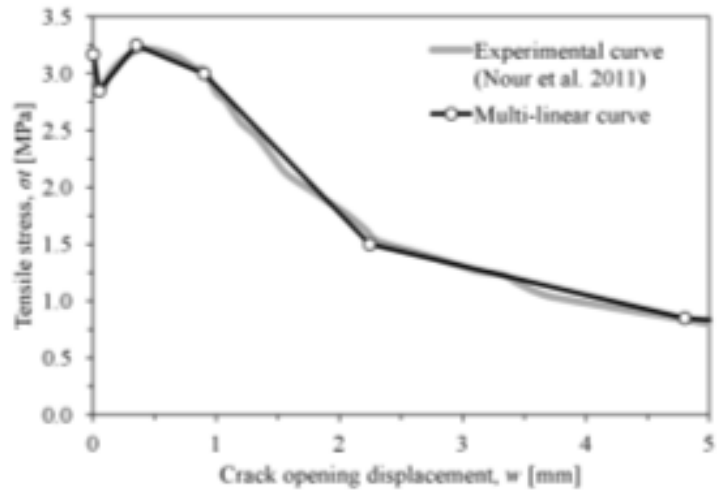

b)

Fig. 21: a) Force-central deflection relationship of RPT-3ps obtained experimentally [41], b) stress-crack width response of the SFRC of the RPT-3ps [41].

To assess the predictive performance of the proposed model when applied to RPT-3ps, the results of the experimental program presented in [41] were considered. In Fig. 21a is represented the force vs. central deflection of two round panels (designated by panel D2 and D4) of a diameter of $800 \mathrm{~mm}$, a thickness of $80 \mathrm{~mm}$, and a span radius (distance between support and centre of the panel) of $375 \mathrm{~mm}$ that were tested according to the ASTM C1550 [23] recommendations (Fig. 11c). The panels were made of a SFRC reinforced with $60 \mathrm{~kg} / \mathrm{m}^{3}$ of steel fibres with a length, diameter, and aspect ratio of $60 \mathrm{~mm}, 0.75 \mathrm{~mm}$, and 80, respectively. The post-cracking response in terms of stress-crack width relationship $(\sigma-w)$ of this SFRC was obtained through direct tensile tests (DTT), whose average curve is represented in Fig. 21b [41]. This figure also includes the diagram formed by several linear branches that best fits the experimental curve that was used in the simulation.

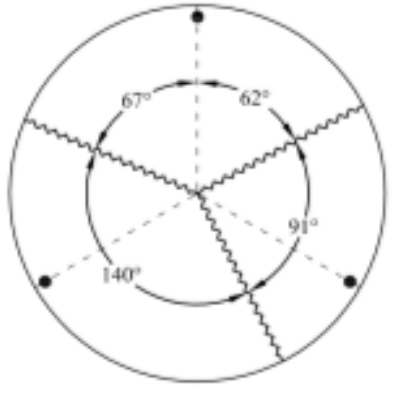

a)

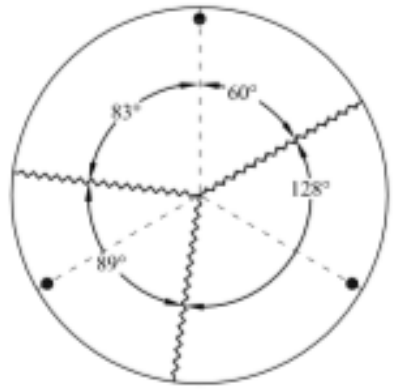

b) 
Fig. 22: Failure mechanism of the RPT-3ps panels: a) panel D2, and b) panel D4 [41].

Moreover, the simplified cracking patterns of Fig. 22, experimentally registered for the panels in [41], were adopted in the model to achieve the envelope of the model prediction as represented in Fig. 23.

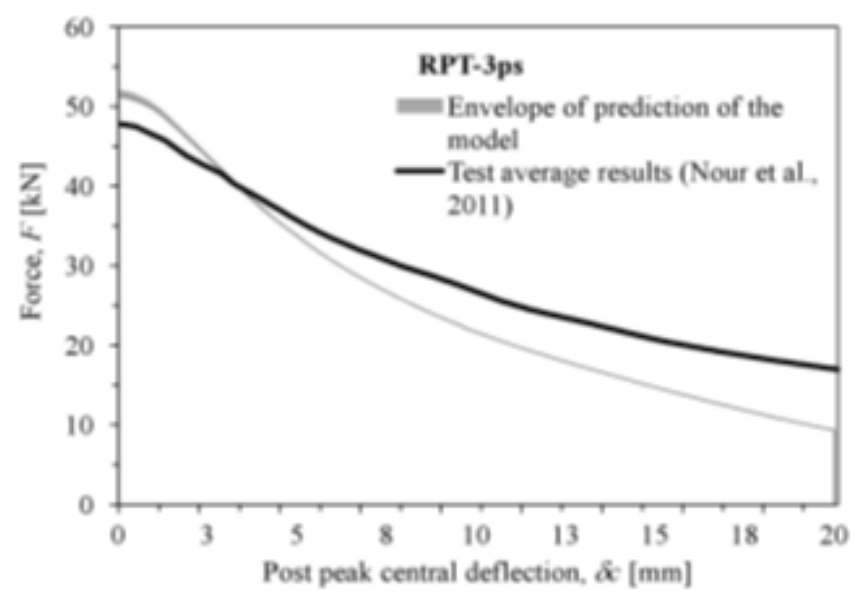

Fig. 23: Force vs. post peak central deflection of RPT-3ps reported in [41] and predicted by the model.

Fig. 23 presents the average force vs. post peak central deflection obtained experimentally, and the envelope of this relationship determined by the developed model, where it can be concluded that the model is capable of capturing the peak load and the post-peak behaviour of this type of panels with acceptable accuracy, by taking into account the $\sigma-w$ obtained from DTT. This envelope response, obtained with the simulations, is due to the variation of the crack patterns of Fig. 22 considered in the simulations. The quite small width of this envelope indicates that the inclination of cracks has relatively small impact on this type of relationship when the number of radial cracks is preserved constant. When the predictive performance of the model applied to SPT-css (Fig. 20) is compared to the one obtained on the simulations of the RPT-3ps (Fig. 23), the performance was not so good in the last type of panels. However, the justification for this different level of predictive performance is due to the distinct strategy adopted to derive the $\sigma-w$ used in the model. In fact, while in the simulations of the SPT-css the $\sigma-w$ was obtained from the tests executed in specimens extracted from the panels, and therefore are representative of the fibre distribution and orientation of the SFRC applied in the panel, in the simulations of the RPT-3ps the $\sigma-w$ was 
determined from the results obtained in DTT tests executed with cast specimens, whose fibre distribution and orientation do not represent properly the SFRC in the panel.

\section{Parametric study}

By using the developed numerical model, the influence of the post-cracking response of FRC on the load carrying capacity of a RPT simply supported in its contour (RPT-css) was evaluated executing a parametric study conducted on a round panel with a diameter of $1500 \mathrm{~mm}$ and a thickness of $150 \mathrm{~mm}$, and subjected to a point load in its centre (Fig. 24a) [12].

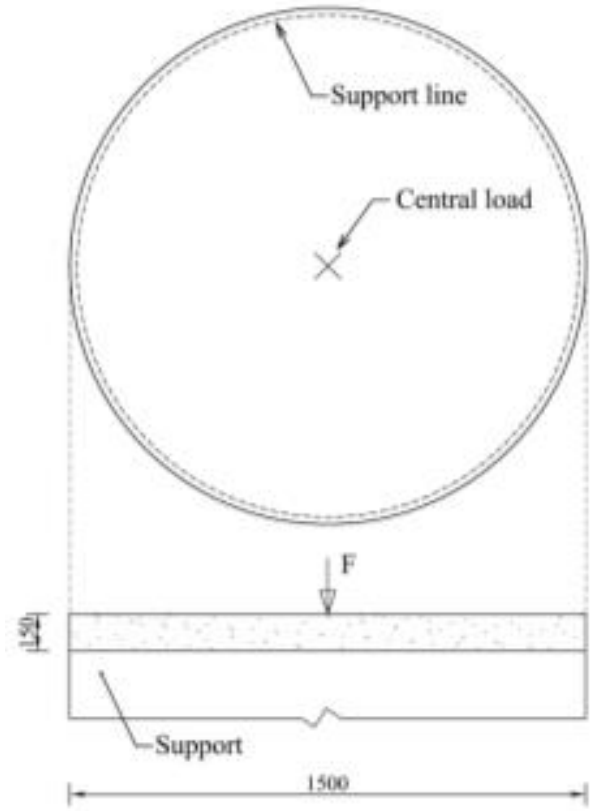

a)
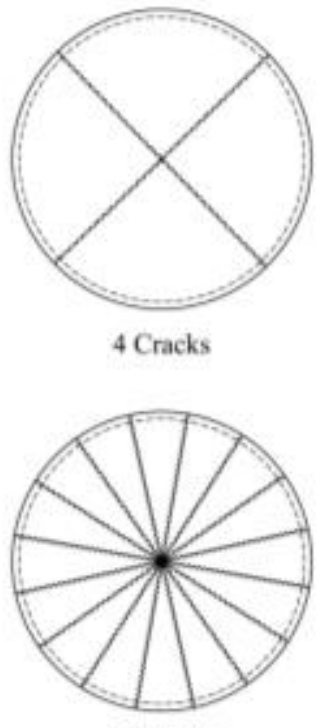

16 Cracks

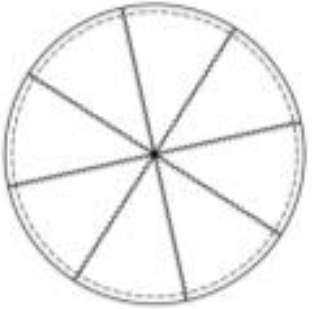

8 Cracks

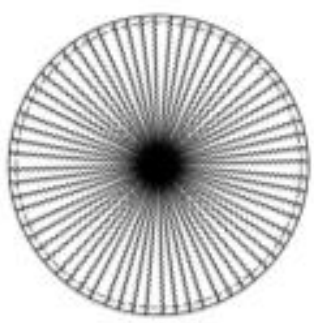

64 Cracks

b)

Fig. 24: a) Geometry of the RPT-css; b) cracks patterns considered in the parametric study (dimension in mm).

In the performed parametric study the C60 concrete strength class ( $\left.f_{c k}=60 \mathrm{MPa}\right)$ was used and, as indicated in

Table 4, four FRC of different toughness classes, classified as 6a, 6d, 12a, and 12d according to the recommendations of fib MC-2010 [19], were considered. 
Table 4: Adopted FRC toughness classes according to the fib MC-2010 [19]

\begin{tabular}{cccc}
\hline Case study & $\begin{array}{c}\text { Toughness } \\
\text { class }\end{array}$ & $\begin{array}{c}\text { Interval of } f_{R 1} \\
{[\mathrm{MPa}]}\end{array}$ & $\begin{array}{c}\text { Interval of } \\
f_{R 3} / f_{R 1}\end{array}$ \\
\hline FRC-6a & $6 \mathrm{a}$ & {$[6-7]$} & {$[0.5-0.7]$} \\
FRC-6d & $6 \mathrm{~d}$ & {$[6-7]$} & {$[1.1-1.3]$} \\
FRC-12a & $12 \mathrm{a}$ & {$[12-13]$} & {$[0.5-0.7]$} \\
FRC-12d & $12 \mathrm{~d}$ & {$[12-13]$} & {$[1.1-1.3]$} \\
\hline
\end{tabular}

In this toughness classification the number and the letter $(a, b, c, d$ or $e)$ represent the intervals for, respectively, the $f_{R 1 k}$ and $f_{R 3 k} / f_{R 1 k}$ ratio. $f_{R 1 k}$ and $f_{R 3 k}$ are the characteristic values of flexural tensile strength of FRC corresponding to the crack mouth opening displacement of $0.5 \mathrm{~mm}$ and $2.5 \mathrm{~mm}$, respectively, measured in three point bending test on notched beams. For instance, when a material is denoted as " $7 \mathrm{~b}$ ", it has a $f_{R 1 k}$ ranging between 7 and $8 \mathrm{MPa}$, and a $f_{R 3 k} / f_{R 1 k}$ ratio ranging between 0.7 and 0.9 (see Fig. 25).

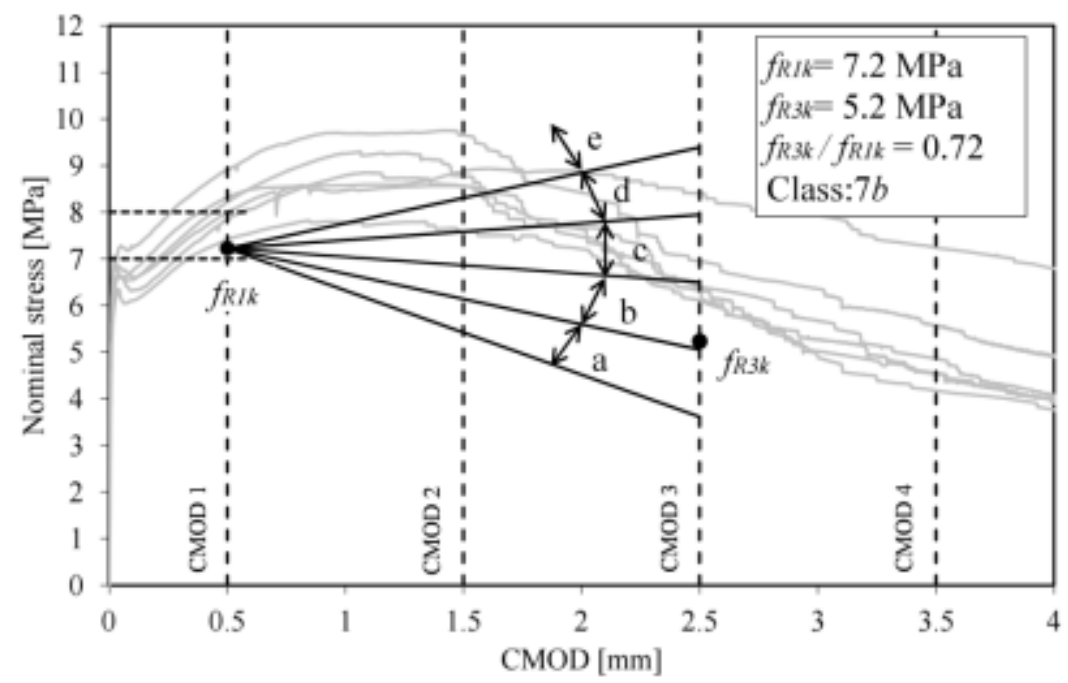

Fig. 25: The concept of toughness class for FRC based on the relationship between the flexural stress and CMOD [19].

In Fig. 26a is schematized the stress-strain diagram recommended by fib MC-2010 for FRC in the ultimate limit state conditions [19]. In this diagram $f_{F t s, k}$ and $f_{F t u, k}$ are the characteristic values of the residual flexural tensile strength at service and ultimate conditions, respectively, determined by applying the following equations [19]: 
$f_{F t s, k}=0.45 f_{R 1, k}$

$f_{F t u, k}=f_{F t s, k}-\frac{w_{u}}{C M O D_{3}}\left(f_{F t s, k}-0.5 f_{R 3, k}+0.2 f_{R 1, k}\right) \geq 0$

where $w_{u}=2.5 \mathrm{~mm}$ is the considered maximum crack opening. In the diagram of Fig. $26 \mathrm{a}, \varepsilon_{A}$ is the strain at the end

of fist linear branch $\left(=0.9 f_{c t, k} / E_{c}\right), \varepsilon_{P}$ is the strain corresponding to the tensile strength $\left(f_{c t, k}\right)$ assumed equal to $0.15 \%$, and $\varepsilon_{S L S}$ and $\varepsilon_{S L U}$ are, respectively, the strain corresponding to $f_{F t s, k}$ and $f_{F t u, k}$ :

$\varepsilon_{S L S}=C M O D_{1} / l_{c s}$

$\varepsilon_{U L S}=\min \left(2 \%, 2.5 / l_{c s}\right)$

where $l_{c s}$ is the structural characteristic length (in $\mathrm{mm}$ ), which is considered equal to the slab thickness (=150 $\mathrm{mm}$ ) [19].

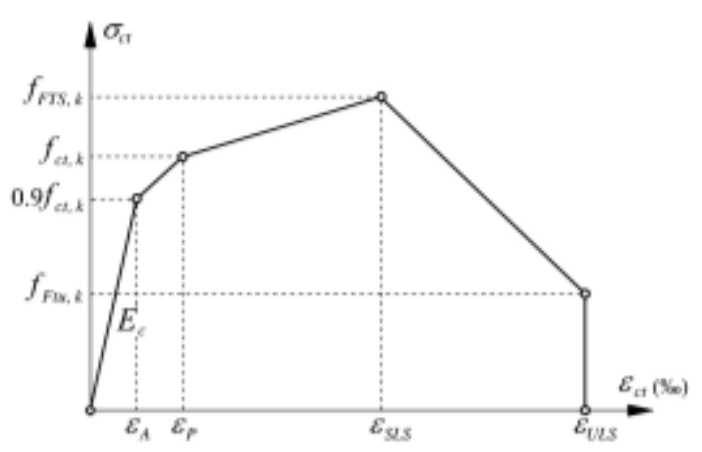

a)

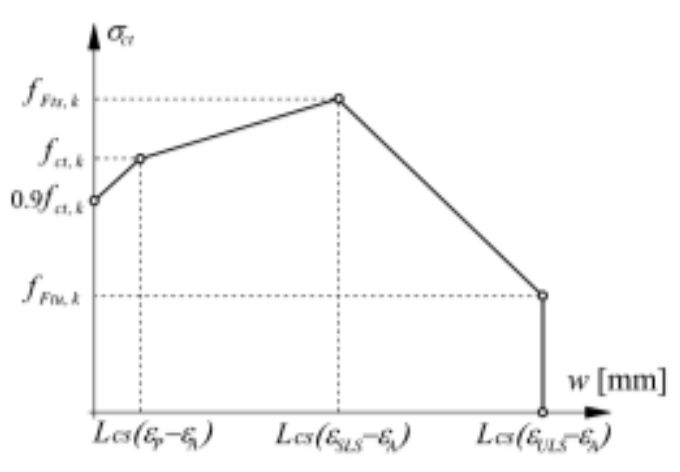

b)

Fig. 26: a) Stress-strain and, b) stress-crack width diagram for FRC according to the recommendations of fib MC$2010[19]$.

By using the concept of structural characteristic length, the stress-strain response of FRC can be converted on the corresponding stress-crack width relationship as schematized in Fig. 26b. By adopting the methodology recommended by fib MC-2010 [19], the post-cracking behaviour of the FRCs of the considered toughness classes (Table 4) are simulated by the diagrams represented in Fig. 27. 


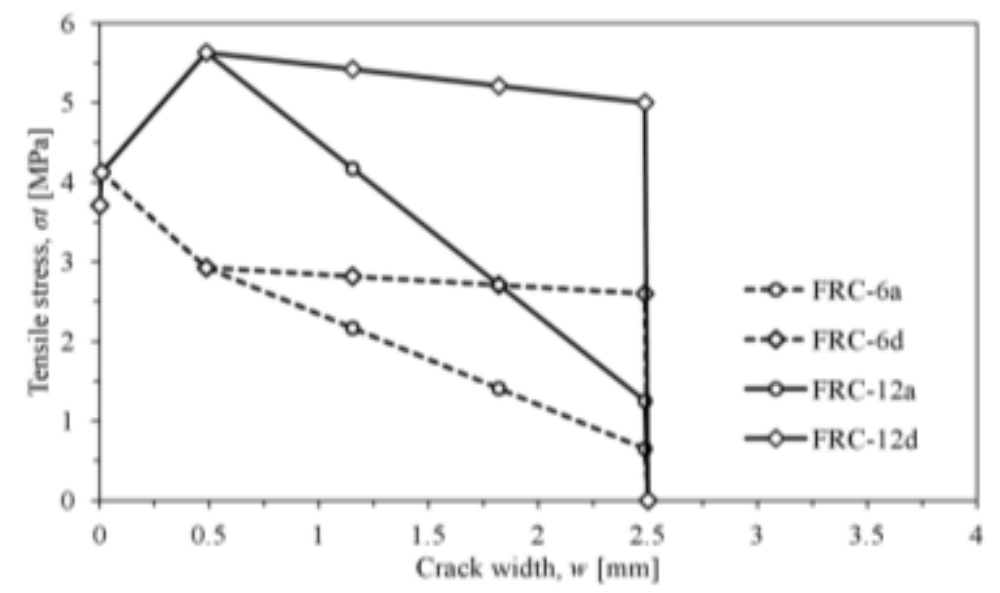

Fig. 27: Stress-crack width diagrams of SFRC of the adopted toughness classes.

In the performed parametric study, by considering the symmetric crack patterns of Fig. 24b, the influence of the number of dominant cracks was evaluated in terms of the force-deflection response of RPT-css when using FRC-6a and FRC-12d, whose results are represented in Fig. 28a and 28b, respectively. According to Fig. 28, adopting larger number of dominant cracks leads to lower structural stiffness (i.e. larger deflection for the same load level) and decreases with the same rate the load carrying capacity of the FRC-6a and FRC-12d panels. A decrease rate of 17\%, $20 \%$, and $21 \%$ is obtained in case of 8,16 , and 64 cracks, with respect to the case when 4 cracks are adopted. However, for both types of FRC (FRC-6a, and FRC-12d), assuming the formation of more than 16 cracks in this type of panel has an impact on the load carrying capacity that do not exceed $1 \%$, which reveals that the loadcarrying capacity of the RPT-css becomes gradually stabilized with the increase of the number of cracks.

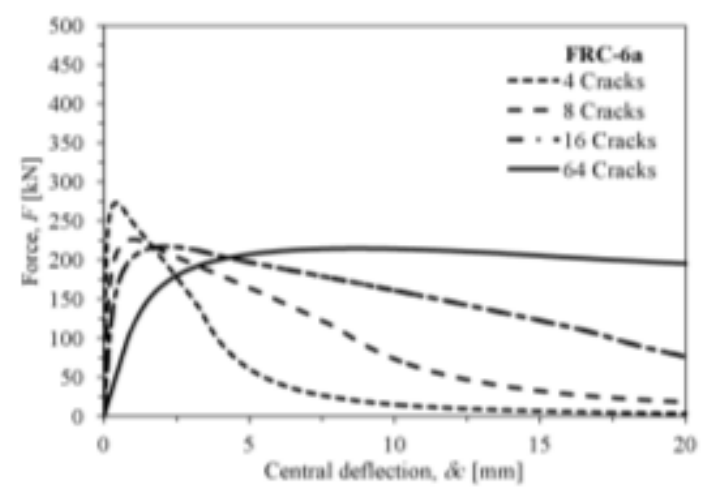

a)

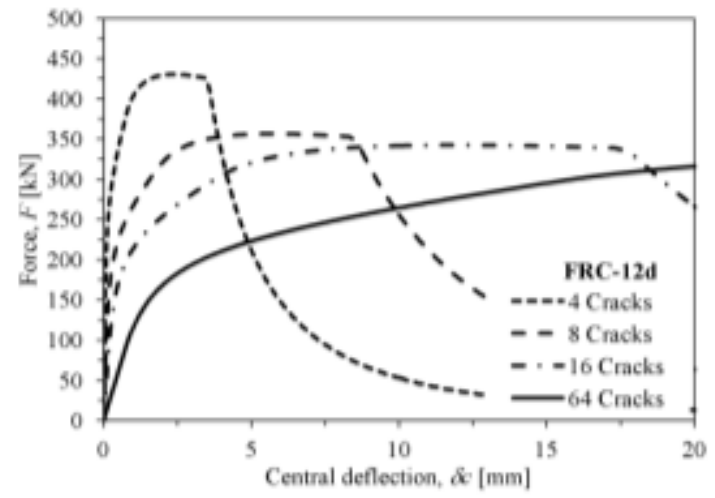

b)

Fig. 28: Influence of the number of cracks on the force-deflection response of RPT-css made by: a) FRC-6a, b)

FRC-12d. 
The impact of the post-cracking behaviour of FRCs on the force-central deflection response and on the corresponding energy-deflection relationship of the RPT-css was evaluated by considering 8 radial cracks, and the obtained results are depicted in Fig. 29a and 29b, respectively.

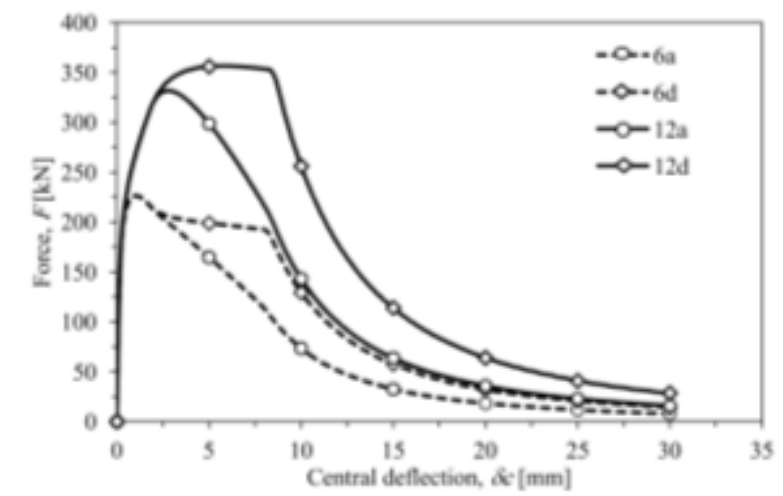

a)

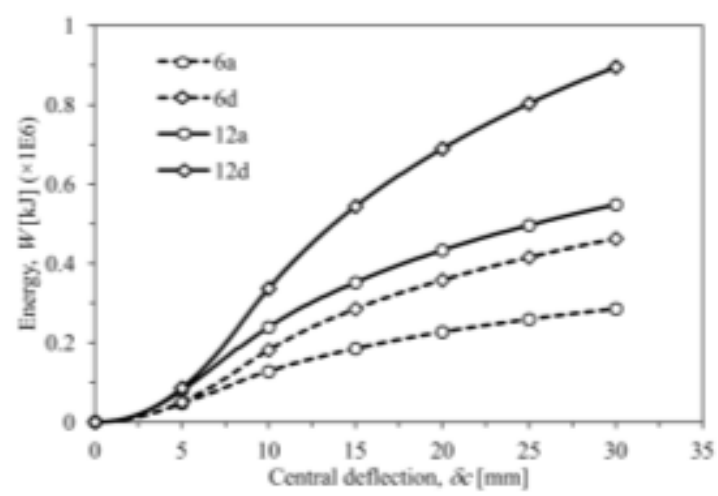

b)

Fig. 29: Influence of the post-cracking response of FRCs on the a) force-deflection, and b) energy-deflection.

From these results it is verified that by increasing the $f_{R l k}$ from $6 \mathrm{MPa}$ to $12 \mathrm{MPa}$ an average increase of 52\% was obtained in terms the load-carrying capacity of the panel. However, the variation of the $f_{R 3 k} / f_{R l k}$ had a much smaller impact on the load carrying capacity of the slab. In fact, an increase of $7.5 \%$ was obtained replacing FRC12a $\left(f_{R 3 k} / f_{R 1 k}=0.7\right)$ by FRC-12d $\left(f_{R 3 k} / f_{R 1 k}=0.9\right)$, while no benefit was registered when FRC-6a was replaced by FRC-6d. The highest impact of the $f_{R 3 k} / f_{R 1 k}$ parameter on the force-central deflection response is in its ductility. The $f_{R 1 k}$ parameter has also a significant influence on the deflection at peak load. In fact, the peak load of the panel was attained at a central deflection of $1.05 \mathrm{~mm}$ in case of FRC-6a and FRC-6d, and $2.8 \mathrm{~mm}$ and $5.65 \mathrm{~mm}$ in case of FRC-12a and FRC-12d, respectively. According to Fig. 29b, the increase of the $f_{R 3 k} / f_{R 1 k}$ parameter has noticeable influence on the energy absorption of the panels, were an average enhancement of $63 \%$ was obtained up to a central deflection of $30 \mathrm{~mm}$ for the both FRC-6d and FRC-12d when compared to FRC-6a and FRC-12a, respectively. The relationship between the force and the average crack width (at bottom surface of the panel) is represented in Fig. 30 for the considered FRC toughness classes and 8 radial cracks adopted in the present parametric study. According to the obtained results, up to the maximum crack width limit recommended by fib MC-2010 [19], i.e. $0.3 \mathrm{~mm}$, the $f_{R 3 k} / f_{R 1 k}$ parameter has no influence in terms of load carrying capacity for both FRC-6 and FRC-12. However, by 
increasing the $f_{R 1 k}$ from 6 to $12 \mathrm{MPa}$ (using FRC-12 instead FRC-6), an increase of 25\% of the load carrying capacity was registered at a crack width of $0.3 \mathrm{~mm}$.
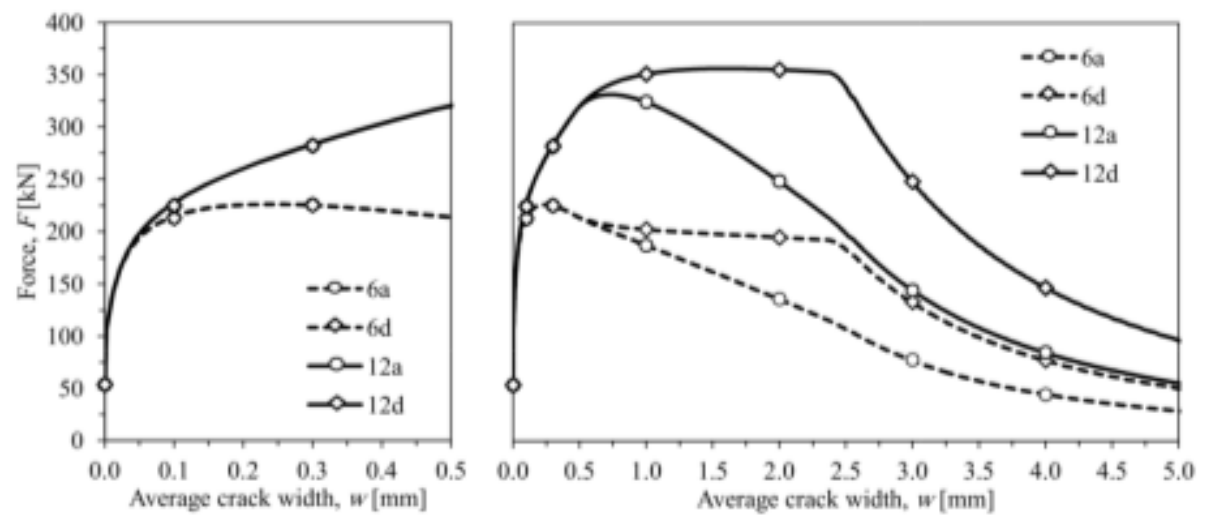

Fig. 30: Influence of the post-cracking response of FRCs on the force-average crack width.

\section{Conclusions}

For deriving the fracture mode I parameters that can be used directly on design approaches for steel fibre reinforced concrete (SFRC) slab type structures, a new type of methodology combining experimental and numerical research was proposed, capable of determining the stress-crack width relationship that takes into account the fibre distribution and orientation caused by the casting conditions in this type of applications. The research program was composed by SFRC square panels tested according to the recommendations of EFNARC, since the formation of several cracks in this type of test captures in a more reliable way the fibre reinforcement mechanisms expected in SFRC slabs. The panels were grouped in two series of the same SFRC strength class, one reinforced with $45 \mathrm{~kg} / \mathrm{m}^{3}$ content of hooked-end steel fibres, and the other with $60 \mathrm{~kg} / \mathrm{m}^{3}$. The tensile post-cracking behaviour of these two SFRCs was determined by executing double edge wedge splitting tests on samples extracted from the tested panels. This test methodology captures correctly the influence of fibre orientation and distribution on the stress-crack width relationship obtained by applying an inverse analysis to the obtained results. To have an explicit representation of the influence of the tensile post-cracking behaviour of SFRC on the load carrying capacity of SFRC panels, a numerical model was developed that considers work equilibrium conditions, the tensile properties of SFRC, and 
uses a moment-rotation approach. The model can be applied to square and round panels made of any type of fibre reinforced concrete (FRC), and its predictive performance was appraised by simulating experimental tests found in available bibliography, and those carried out in the present research. By using the proposed model, the influence of the post-cracking response of FRC on the load carrying capacity of a round panel with relatively large dimensions, and simply supported in its contour, was evaluated under centric load by executing a parametric study. It was demonstrated that the panel's ductility increases significantly with the number of cracks, while the load carrying capacity is not significantly affected. In this study four toughness classes of FRC were selected, by considering the

characteristic values of the flexural tensile strength parameters of FRC ( $f_{R 1 k}$ and $\left.f_{R 3 k}\right)$, as recommended by fib MC2010. For the 8 radial cracks considered, an increase of $52 \%$ and $25 \%$ was obtained for the load carrying capacity of the panel and the load corresponding to the serviceability limit states, respectively. Moreover, the energy absorption of the panel was noticeably influenced by the $f_{R 3 k} / f_{R 1 k}$ ratio, where an increase of $63 \%$ was obtained when the $f_{R 3 k} / f_{R 1 k}$ parameter increases between 0.7 and 0.9 .

\section{Acknowledgements}

This work is supported by the FEDER funds through the Operational Program for Competitiveness Factors COMPETE and National Funds through FCT - Portuguese Foundation for Science and Technology under the project SlabSys-HFRC-PTDC/ECM/120394/2010. The first author acknowledges the FCT PhD Grant SFRH/BD/71934/2010. The authors would like to acknowledge the materials supplied by Maccaferri (fibres), SECIL (cement), SIKA and BASF (superplasticizers), OmyaComital (limestone filler), and Pegop (Fly ash). Special thanks for CiviTest Company that developed the SFRCs and executed the specimens of the experimental program.

\section{References}

[1] Nanni A, Johari A. RCC Pavement Reinforced with Steel Fibers. ACI Materials Journal. 1989;13(3):54-60.

[2] Naaman AE. High Performance Fiber Reinforced Cement Composites In: Shi C, Mo YL, editors. HighPerformance Construction Materials - Science and Applications: World Scientific Publishing Co. Pte. Ltd.; 2008.

[3] Barros JAO, Gouveia-Gouveia A, Sena-Cruz JM, Azevedo AFM, Antunes JAB. Design methods for steel fibre reinforced concrete industrial floors. Third International Conference of Construction Materials: Performance, Innovations and Structural Implications. Vancouver, Canada2005.

[4] Li VC, Stang H, Krenchel H. Micromechanics of crack bridging in fibre-reinforced concrete. Materials and Structures. 1993;26(8):486-94. 
[5] Naaman AE, Shah SP. Pull-Out Mechanism in Steel Fiber-Reinforced Concrete. ACI Journal, Structural Division, ASCE. 1976;102(8):1537-48.

[6] Pereira E, Barros JAO, Camões A. Steel Fiber-Reinforced Self-Compacting Concrete: Experimental Research and Numerical Simulation. Journal of Structural Engineering. 2008;134(8):1310-21.

[7] Taheri M, Barros JAO, Salehian H. Parametric Study of the Use of Strain Softening/Hardening FRC for RC Elements Failing in Bending. Journal of Materials in Civil Engineering 2012;24(3):259-74.

[8] Barros JAO, Taheri M, Salehian H, Mendes PJD. A design model for fibre reinforced concrete beams prestressed with steel and FRP bars. Composite Structures. 2012;94(8):2494-512.

[9] Barros JAO, di Prisco M, di Prisco C. Modelling FRC infrastructures taking into account the soil-structure interaction. Congresso de Métodos Numéricos em Engenharia 2009. Barcelona, Spain2009.

[10] Barros JAO, Salehian H, Pires NMMA, Gonçalves DMF. Design and testing elevated steel fibre reinforced self-compacting concrete slabs. Eighth RILEM International Symposium on Fibre Reinforced Concrete (BEFIB2012): Challenges and opportunities. Guimaraes, Portugal2012.

[11] Salehian H, Barros JAO. Design of elevated steel fibre reinforced self-compacting concrete slabs. Guimaraes, Portugal: Department of Civil Engineering, School Engineering, University of Minho; 2011.

[12] Mobasher B, Destrée X. Design and Construction Aspects of Steel Fiber-Reinforced Concrete Elevated Slabs. In: C. Aldea LF, editor. SP-274 Fiber Reinforced Self-Consolidating Concrete: Research and Applications2010. p. 95-107.

[13] Destrée X. Structural application of steel fibres as only reinforcing in free suspended elevated slabs: conditions - Design examples. In: di Prisco M, Felicetti R, Plizzari GA, editors. Sixth RILEM symposium on fibre-reinforced concretes (BEFIB 2004). Varenna: RILEM; 2004. p. 1073-82.

[14] Johansen KW, Johansen K. Yield-line theory: Cement and Concrete Association London; 1962.

[15] Baumann R, Weisgerber F. Yield-Line Analysis of Slabs-on-Grade. Journal of Structural Engineering. 1983;109(7):1553-68.

[16] Barros JAO. Technology, design and applications of steel fibre reinforced self-compacting concrete. Sixth International Conference of Fibre Concrete - Technology, Design, Application. Prague, Czech: Czech Technical University 2011.

[17] Naaman AE, Fischer G, Krstulovic-Opara N. Measurement of tensile properties of fiber reinforced concrete: draft submitted to ACI Committee 544. In: Naaman AE, Reinhardt HW, editors. 5th international RILEM workshop on high performance fiber reinforced cement composites ( HPFRCC5). Mainz, Germany: RILEM Publications; 2007. p. 3-12.

[18] Mechtcherine V. Testing behaviour of strain hardening cement-based composites in tension-summary of recent research. In: Naaman AE, Reinhardt HW, editors. 5th international RILEM workshop on high performance fiber reinforced cement composites ( HPFRCC5). Mainz, Germany: RILEM Publications; 2007. p. $13-122$.

[19] fib Model Code 2010 - Final draft: CEB and FIP; 2011.

[20] ACI-544.2R. Measurement of properties of fibre reinforced concrete. ACI Materials Journal. 1988:583-93.

[21] ASTM-C-1018-97. Standard Test Method for Flexural Toughness and First-Crack Strength of Fibre-Reinfroced Concrete (using beam with third point loading). Philadelphia, USA: ASTM; 1998.

[22] EFNARC. Specification and Guidelines for Self-Compacting Concrete. 2002. p. 32.

[23] ASTM C1550-05, Standard Test method for Flexural Toughness of Fiber Reinforced Concrete (Using Centrally Loaded Round Panel). West Conshohocken, PA, USA: ASTM Internationa; 2005.

[24] Marti P, Pfyl T, Sigrist V, Ulaga T. Harmonized Test Procedures for Steel Fiber-Reinforced Concrete. ACI Materials Journal. 1999;96(6):676-86.

[25] Khaloo AR, Afshari M. Flexural behaviour of small steel fibre reinforced concrete slabs. Cement and Concrete Composites. 2005;27(1):141-9. 
[26] Nour A, Massicotte B. Use of tension softening diagrams for predicting the postcracking behaviour of steel fibre reinforced concrete panels. 6th International Conference on Fracture Mechanics of Concrete and Concrete Structures. Catania, Italy2007. p. 1533-40.

[27] Taheri M, Barros JAO. An analytical model to simulate tension stiffening mechanism in moment-rotation response of FRC flexural members with tensile longitudinal reinforcement. Guimaraes, Portugal: University of Minho; 2012. p. 34.

[28] Pereira ENB. Steel Fibre Reinforced Self-compacting Concrete: from material to mechanical behaviour. Guimaraes, Portugal: University of Minho; 2006.

[29] Eurocode 206-1. Concrete - Part 1: Specification, performance, production and conformity. . European standard; 2000. p. 69.

[30] Abrishambaf A, Barros JAO, Cunha VMCF. Relation between fibre distribution and post-cracking behaviour in steel fibre reinforced self-compacting concrete panels. Cement and Concrete Research. 2013;51(0):57-66.

[31] di Prisco M, Ferrara L, Lamperti ML. Double edge wedge splitting (DEWS): an indirect tension test to identify post-cracking behaviour of fibre reinforced cementitious composites. Materials and Structures. 2013;46(11):1893918.

[32] Barros JAO, Cunha VMCF, Ribeiro AF, Antunes JAB. Post-cracking behaviour of steel fibre reinforced concrete. Materials and Structures. 2005;38(1):47-56.

[33] Laranjeira F. Design-oriented constitutive model for steel fiber reinforced concrete: Universitat Politècnica de Catalunya; 2010.

[34] Bjøntegaard Ø. Energy absorption capacity for fibre reinforced sprayed concrete. Effect of friction in round and square panel tests with continuous support (Series 4). Statens vegvesen, Norwegian Public Roads Administration Directorate of Public Roads Technology Department; 2009. p. 34.

[35] Vipulanandan C, Paul E. Performance of epoxy and polyester polymer concrete. ACI Materials Journal. 1990;87(3):241-51.

[36] Barros JAO, Figueiras J. Flexural Behavior of SFRC: Testing and Modeling. Journal of Materials in Civil Engineering. 1999;11(4):331-9.

[37] van Mier JGM. Fracture Processes of Concrete: CRC Press; 1997.

[38] Divakar M, Fafitis A, Shah S. Constitutive Model for Shear Transfer in Cracked Concrete. Journal of Structural Engineering. 1987;113(5):1046-62.

[39] Visintin P. A generic segmental analysis of all type of RC members. Adelaide, Australia: University of Adelaide; 2012.

[40] Taheri M, Barros JAO, Salehian H. A design model for strain-softening and strain-hardening fiber reinforced elements reinforced longitudinally with steel and FRP bars. Composites Part B: Engineering. 2011;42(6):1630-40.

[41] Nour A, Massicotte B, De Montaignac R, Charron J-P. Derivation of a crack opening deflection relationship for fibre reinforced concrete panels using a stochastic model: Application for predicting the flexural behaviour of round panels using stress crack opening diagrams. Cement and Concrete Research. 2011;41(9):964-74. 


\section{LIST OF TABLE CAPTIONS}

Table 1: Compositions of the SFRSCCs used in the experimental program [per $1 \mathrm{~m}^{3}$ ]

Table 2: Material properties of the SFRSCCs used in the experimental program

Table 3: Parameters defining the stress-crack width diagrams (Figs. 10 and 19a) obtained from DEWST

Table 4: Adopted FRC toughness classes according to the fib MC-2010 [19] 


\section{LIST OF FIGURES CAPTIONS}

Fig. 1: Details of the double edge wedge splitting test; a) sample shape, b) geometry of the "V" notch, c) test setup (dimensions in $\mathrm{mm}$ ).

Fig. 2: Comparison between stress-CMOD relationship of DTT and DEWST.

Fig. 3: Envelope and average tensile stress-CMOD relationship of the DEWST: a) FRC45, b) FRC60.

Fig. 4: Test setup of the SPT-css (dimensions in $\mathrm{mm}$ ).

Fig. 5: Ultimate crack patterns of the square panels of series: a) SP45, b) SP60.

Fig. 6: Force-central deflection of SPT-css in series: a) SP45, and b) SP60.

Fig. 7: Energy absorption vs. central deflection of SPT-css in series: a) SP45, and b) SP60.

Fig. 8: Compressive behaviour of a FRC: a) pre-peak stress-strain response, b) post-peak stress-deformation response, c) sliding of a concrete wedge along radial crack on the top compressed face of a panel.

Fig. 9: a) Concrete wedge shear sliding in the compression zone of a bending element, b) concrete element under compression, c) stresses and displacement of the wedge.

Fig. 10: Tensile behaviour of a FRC: a) stress-strain pre-peak response, b) post-peak stress-crack width response. Fig. 11: Crack pattern and deformation of panel in: a) SPT-css, b) RPT-css, and c) RPT-3ps.

Fig. 12: Upward deflection of slab with respect to support line.

Fig. 13: Representation of imaginary pivots and rotational axes of uncracked plates in: a) SPT-css, and b) RPT-css. Fig. 14: a) Rigid rotation of intact plates in SPT-css, and b) crack rotation analysis in SPT-css.

Fig. 15: Crack rotation analysis in RPT-3ps.

Fig. 16: a) Cracked FRC segment of length submitted to pure bending, and b) layer approach to discretize the cross section.

Fig. 17: Flowchart of the algorithm adopted in the developed model.

Fig. 18: Crack patterns registered experimentally (grey colour) and considered for the simulations (straight black lines) in: a) SP45, and b) SP60.

Fig. 19: a) Multi-linear post-cracking response of the FRCs, b) Moment-rotation response of a cross section of unit width of a square panel made with FRC45 and FRC60.

Fig. 20: Relationship between load and the deflection after crack initiation (average experimental results and envelope of the model's prediction) in SPT-css tests of series: a) SP45, and b) SP60. 
Fig. 21: a) Force-central deflection relationship of RPT-3ps obtained experimentally [41], b) stress-crack width response of the SFRC of the RPT-3ps [41].

Fig. 22: Failure mechanism of the RPT-3ps panels: a) panel D2, and b) panel D4 [41].

Fig. 23: Force vs. post peak central deflection of RPT-3ps reported in [41] and predicted by the model.

Fig. 24: a) Geometry of the RPT-css; b) cracks patterns considered in the parametric study (dimension in mm).

Fig. 25: The concept of toughness class for FRC based on the relationship between the flexural stress and CMOD [19].

Fig. 26: a) Stress-strain and, b) stress-crack width diagram for FRC according to the recommendations of fib MC$2010[19]$.

Fig. 27: Stress-crack width diagrams of SFRC of the adopted toughness classes.

Fig. 28: Influence of the number of cracks on the force-deflection response of RPT-css made by: a) FRC-6a, b) FRC-12d.

Fig. 29: Influence of the post-cracking response of FRCs on the a) force-deflection, and b) energy-deflection. Fig. 30: Influence of the post-cracking response of FRCs on the force-average crack width. 